Published in final edited form as:

J Allergy Clin Immunol Pract. 2017 ; 5(3): 547-563. doi:10.1016/j.jaip.2017.01.025.

\title{
Severe delayed cutaneous and systemic reactions to drugs: a global perspective on the science and art of current practice
}

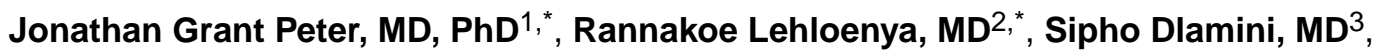 \\ Kimberly Risma, MD $^{4}$, Katie D. White, MD, PhD $^{5}$, Katherine C. Konvinse, BA ${ }^{6}$, and Elizabeth \\ J. Phillips, MD ${ }^{5,6,7,8, \dagger}$ \\ ${ }^{1}$ Division of Allergology and Clinical Immunology, Department of Medicine, University of Cape \\ Town \\ ${ }^{2}$ Division of Dermatology, Department of Medicine, University of Cape Town \\ ${ }^{3}$ Division of Infectious Diseases, Department of Medicine, University of Cape Town \\ ${ }^{4}$ Division of Allergy, Cincinnati Children's Hospital Medical Center, Department of Pediatrics, \\ University of Cincinnati College of Medicine \\ ${ }^{5}$ Department of Medicine, Vanderbilt University Medical Center, Nashville, TN \\ ${ }^{6}$ Department of Pathology, Microbiology and Immunology, Vanderbilt University Medical Center, \\ Nashville TN \\ ${ }^{7}$ Department of Pharmacology, Vanderbilt University School of Medicine, Nashville TN \\ ${ }^{8}$ Institute for Immunology \& Infectious Diseases, Murdoch University, Murdoch, Western Australia, \\ Australia
}

\section{Abstract}

The majority of immune-mediated adverse drug reactions (IM-ADRs) involve the skin, and many have additional systemic features. Severe cutaneous adverse drug reactions (SCAR) are an uncommon, potentially life-threatening and challenging sub-group of IM-ADRs with diverse clinical phenotypes, mechanisms and offending drugs. T-cell mediated immunopathology is central to these severe delayed reactions, but effector cells and cytokines differ by clinical phenotype. Strong HLA-gene associations have been elucidated for specific drug-SCAR IMADRs such as Stevens-Johnson Syndrome/toxic epidermal necrolysis (SJS/TEN); although the mechanisms by which carriage of a specific HLA allele is necessary but not sufficient for the development of many IM-ADRs is still being defined. SCAR management is complicated by substantial short and long-term morbidity/ mortality and the potential need to treat ongoing comorbid disease with related medications. Multidisciplinary specialist teams at experienced units

\footnotetext{
${ }^{\dagger}$ Corresponding author: Elizabeth J. Phillips, MD, FIDSA, FAAAAI, $116121^{\text {St }}$ Avenue South, A-2200, Vanderbilt University Medical Center, Nasvhille, TN 37232, elizabeth.j.phillips@vanderbilt.edu, (615) 322-9174 (tel); (615) 343-6160.

*Equally contributing authors

Publisher's Disclaimer: This is a PDF file of an unedited manuscript that has been accepted for publication. As a service to our customers we are providing this early version of the manuscript. The manuscript will undergo copyediting, typesetting, and review of the resulting proof before it is published in its final citable form. Please note that during the production process errors may be discovered which could affect the content, and all legal disclaimers that apply to the journal pertain.
} 
should care for patients. In the setting of SCAR, patient outcomes as well as preventive,diagnostic, treatment and management approaches are often not generalizable, but rather context specific, driven by population HLA-genetics, the pharmacology and genetic risk factors of the implicated drug, severity of underlying co-morbid disease necessitating ongoing treatments, and cost considerations. In this review, we update the basic and clinical science of SCAR diagnosis and management.

\section{Keywords}

Severe cutaneous adverse drug reactions; immune-mediated adverse drug reactions; HLA; DRESS; SJS/TEN; T cell

\section{Introduction}

Therapeutics is a cornerstone of modern medical practice. The United States Federal Drug Agency has approved 1450 new molecular entities (NME), with 25-35 NME approved per year (1). Adverse drug reactions (ADRs) to known and new agents are common, accounting for around $5 \%$ and $3 \%$ of adult medical and paediatric hospital admissions respectively (2, 3). ADRs may result from 'on-target' effects, predictable based on drug action (type A); in contrast, 'off-target' ADRs (type B) are a heterogeneous group with varied clinical manifestations and underlying mechanism. Subspecialists such as hepatologists, allergists/ clinical immunologists and dermatologists are the usual disciplines that investigate and manage off-target ADRs, given the frequency of liver and cutaneous involvement as well as the proposed central role of immunopathology. Figure 1 illustrates how cutaneous, with and without systemic 'off-target', ADRs can occur through several mechanisms. In this review, we will discuss cutaneous adverse drug reactions (CADR) with a special focus on severe cutaneous adverse drug reactions (SCAR), which are life-threatening T-cell mediated 'offtarget' CADRs. SCAR includes distinct clinical phenotypes with varied complex underlying immunological mechanisms. Clinicians managing patients presenting with possible SCAR face multiple challenges including: a growing number of SCAR-causing drugs; continued reliance on case definitions in the absence of either accurate and/or well-standardised diagnostics/biomarkers; and no discriminatory or good prognostic markers to tailor treatment approaches or prevent drug cessation in less severe variants. We outline for practicing clinicians, the existing basic and clinical science evidence base for the prevention, diagnosis and management of severe cutaneous and systemic reactions to drugs.

\section{Epidemiology}

CADRs are common, and can be found listed amongst the side effects of almost all drugs. Non-life threatening CADRs such as maculopapular exanthema/morbilliform eruptions, photodistributed drug eruptions, fixed drug eruption (FDE) and urticaria are frequent with estimates between $0.3-8 \%$, with antibiotics and NSAIDs drugs being the commonest offenders $(4,5)$. In certain high-risk patient populations, such as persons living with HIV, CADRs have been reported to occur in up to $25 \%$ of patients receiving highly active antiretroviral therapy (HAART) $(6,7)$. Clinicians need to be able to distinguish the distinct 
clinical phenotypes of the more severe reactions (detailed in the next section), with high morbidity and mortality, from this high background rate of CADRs.

Figure 2 highlights the estimated prevalence of major SCAR phenotypes in different continents, with the common offenders and regionally important drugs highlighted. The influence of population-specific HLA risk alleles is also shown for abacavir hypersensitivity (HLA-B*57:01), allopurinol drug Reaction with eosinophilia and systemic symptoms (DRESS)/drug-induced hypersensitivity syndrome (DIHS)/hypersensitivity with systemic symptoms (HSS) (HLA-B58*01) and carbamazepine Stevens Johnson syndrome/toxic epidermal necrolysis (SJS/TEN) (HLA-B*15:02). Globally, SJS/TEN and DRESS are the two commonest SCAR clinical phenotypes with a prevalence of between 1-7/million population and 1-4/10000 respectively. SJS/TEN increases almost a 1000-fold to as high as 2/1000 amongst persons living with HIV (8-18). Epidemiological data on acute generalized exanthematous pustulosis (AGEP) is limited but is estimated at between $0.35-5 /$ million population $(11,19)$. Other CADRs that tend to have self-limiting phenotypes, but also have uncommon severe forms include fixed drug eruptions (FDE) with a severe generalised bullous subtype, and drug-induced vasculitis. Limited datasets are available on the prevalence of these ADRs although they have been well described in association with antimicrobials and NSAIDs $(20,21)$.

Common offending drugs causing SCAR include allopurinol (highest single offending agent in Europe, China and USA) (22, 23), aromatic anticonvulsants (leading cause of DRESS), antimicrobials e.g. co-trimoxazole, antiretrovirals e.g. abacavir and nevirapine, and oxicams, a class of non steroidal anti-inflammatory drug (NSAID) (Figure 2). Table 2 shows commonly implicated drugs stratified by phenotype, indicating that certain drugs e.g. aromatic anticonvulsants associate with particular phenotypes e.g. DIHS/DRESS, while others traverse phenotypes. The key drivers of particular offending agents epidemiology includes: population frequency of drug specific HLA-risk alleles which will be discussed further in the immunopathogenesis section of this review $(17,24)$ (Figure 2); and local disease burden and risk factors; such as the co-epidemics of tuberculosis and human immunodeficiency virus (HIV) leading to the disproportionate TB and cotrimoxazole-related SCAR prevalence in sub-Saharan Africa (10, 25). Non-genetic risk factors are also important for certain SCAR phenotypes and particular offending drugs including i) concommittant diuretic use, higher dosing and pre-existing renal impairment in allopurinol hypersensitivity $(22,23)$, and ii) underlying malignancy (26) or systemic lupus erythematosus (SLE) (27) increasing the risk of SJS/TEN. It is also important to note that certain clinical phenotypes of SCAR e.g. SJS/TEN and AGEP, especially in children and younger populations are not always associated with drugs, postulated to be attributed in some instances to viral, bacterial or even parasitic infections $(19,28)$.

\section{Clinical phenotypes}

The clinical presentations of CADRs have some overlapping features that may make it difficult to identify the phenotype. In this section we describe these features, summarizing cutaneous and systemic involvement, latency periods, laboratory and histological features as 
well as differential diagnoses in Table 2, with illustrative images showing discriminatory cutaneous features in Figure 3.

Exanthematous, morbilliform or maculopapular drug eruptions account for $95 \%$ of all cutaneous drug eruptions (29). The symmetrical erythematous macules and papules can become confluent and generalized. Exanthematous drug eruption may be associated with pruritus, low-grade fever and mild eosinophilia. The majority are self limiting allowing continuation of the drug. However, care should be taken as a small proportion progress to more serious reactions such as SJS/TEN and DRESS (30).

\section{Steven Johnson syndrome (SJS) and toxic epidermal necrolysis (TEN)}

SJS and TEN form a spectrum of the same disease differentiated by the extent of epidermal necrosis and detachment. In SJS, there is $<10 \%$ of epidermal detachment and in TEN there is $>30 \%$. SJS/ TEN overlap lies between the two extremes. SJS/TEN is a different disease from erythema multiforme which has mainly an infective etiology $(31,32)$. SJS/TEN is often preceded by a prodrome of fever, general malaise, non productive cough, stinging eyes and a sore mouth. These symptoms and signs are often confused with an upper respiratory tract infection. They rapidly progress to an exanthem of macules and targetoid lesions, epidermal detachment and erosive mucositis of at least two surfaces, usually within 3 days (33). Early painful erythema of the palms and soles is a major feature of SJS/TEN. TEN, the more severe form has mortality of $>30 \%$ which gradually increases up to $49 \%$ at one year (34). Risk factors for SJS/TEN include HIV infection, certain HLA alleles that may be population clustered, renal failure and radiotherapy $(7,35)$.

\section{Drug reaction with eosinophilia and systemic symptoms (DRESS)}

DRESS, which is also known as drug hypersensitivity syndrome, is another severe form of SCAR. The eruption is most commonly urticaria-like plaques or an exanthem. However, vesicles, pustules, cheilitis, purpura, targetoid lesions and erythroderma have been reported. Fever, edema (particularly facial and acral), lymphadenopathy, leukocyte abnormalities (leucocytosis, eosinophilia and/or atypical lymphocytosis) hepatitis and non-erosive mucositis have been reported with variable frequency. Nephritis, pancreatitis, pneumonitis and myocarditis are less frequently reported $(36,37)$. Long-standing severe lesions are characterized by extensive scaling referred to as exfoliative dermatitis. Involvement of > $50 \%$ of the body surface area, severe oedema, infiltrated skin lesions, scaly erythema and purpura differentiate DRESS from drug exanthems and should serve as a red flag for the treating physician (36). Risk factors for DRESS include renal failure and advanced age.

Fixed drug eruption presents as itchy, round, well-circumscribed, erythematous macules or dusky indurated plaques on the skin or mucosal surfaces. The hallmark of FDE is persistent hyperpigmentation, most severe in darker skin (38). The lesions recur on the same sites within a few hours on re-exposure to the drug, sometimes with new lesions at other sites (39). Rarely, the lesions can be extensive and bullous resembling SJS/TEN but typically without extensive mucositis. Upon discontinuation of the offending drug, lesions resolve spontaneously within 7 to 10 days, even in severe cases, often with post-inflammatory hyperpigmentation (40) (Figure 3). 
Acute generalized exanthematous pustulosis (AGEP)—Characteristically AGEP presents as an acute generalized eruption of non-follicular, sterile pustules on a background of indurated erythema. The pustules have an early predilection for the flexural folds of the face and body and spread to the trunk and limbs within a few hours. Palms and soles are rarely affected and at least one mucous membrane is involved in $20-25 \%$ of cases. Systemic features of AGEP may include fever, leukocytosis, neutrophilia, eosinophilia and hypocalcaemia. Hepatitis, renal insufficiency and respiratory distress are reported less frequently $(41,42)$. The pustules usually resolve spontaneously with a typical collaret of scale-like desquamation within two weeks. AGEP usually has a mild course except in patients with poor general health and the reported mortality is lower than 5\% $(11,43)$. The clinical picture, typical histology of subcorneal and/or intraepithelial pustules and a positive patch test that often displays localized production of sterile pustules on a background of indurate erythema similar to the acute reaction confirms the diagnosis $(41,44)$ Figure 3.

\section{Serum sickness (SS) and Serum sickness-like reactions (SSLR)}

SSLR clinically resembles SS, the latter being the prototype immune complex-mediated hypersensitivity reaction. However, in SSLR there are no circulating immune complexes, serum complement levels are normal and there is typically no evidence of internal organ involvement such as nephritis or hepatitis. Classic SS is characterized by pruritic urticarial or serpiginous plaques, fever, malaise, and polyarthralgia or polyarthritis, 7 - 14 days after first exposure to the responsible agent. In cases where the offending drug is injected, the rash often starts at the site of injection (45-47). The rash is usually widespread however the involvement of the junction between the dorsum and palmoplantar surfaces is suggestive of SS $(48,49)$. Exanthematous eruption, papules, palmar erythema, reticulate purpura and frank vasculitis have been reported. SSLR has similar clinical features but is usually milder than classic SS and all the features may not be present. The most common features include a similar rash, edema, fever and polyarthritis. SSLR rash typically appears 5- 10 days after the first exposure to the offending drug. The disease is self-limiting and resolves spontaneously on withdrawal of the offending drug (50).

\section{Drug-induced vasculitis}

The clinical hallmark of cutaneous vasculitis is palpable purpura. Other less common variants include reticulate purpura and urticarial vasculitis. In severe cases, the purpura can progress to form blisters and deep ulcers. The eruption can be associated with less specific features like fever, malaise, arthralgia and myalgia to single tissue or life-threatening organ specific vasculitis. The kidneys and the lungs are the most commonly affected $(51,52)$

(Figure 3).

\section{Immunopathogenesis}

Seminal observations in the early 2000's identified strong associations between the risk of severe delayed IM-ADR such as SJS/TEN, DRESS, and drug-induced liver disease with variations in class I and class II HLA genes suggesting that CD4+ and/or CD8+ T-cell immune responses form the basis for these syndromes (53-56). This is supported by direct observation of cytotoxic immune cells (primarily T cells, but also NK cells and NKT cells) 
in blister fluid obtained from patients with SJS/TEN and in biopsy specimens of inflamed skin obtained during acute CADR or following epidermal or intradermal administration of causative drug in patients with history of IM-ADR (Figure 4b) (57-60). Additionally, multiple laboratory studies have either provided drug specific ex vivo data to support a T-cell response or shown that circulating $\mathrm{T}$ cells isolated from individuals with history of IM-ADR proliferate in response to specific drugs or their metabolites in an HLA-restricted manner (61-65).

\section{Drug interactions with immune proteins}

Three non-mutually exclusive models have been proposed to describe how drugs might trigger T-cell activation (Figure 4a). These include the hapten/prohapten model, pharmacological interaction (p-i) model, and altered peptide repertoire model. Under the hapten/prohapten model, the offending drug or a reactive metabolite of the drug binds covalently to endogenous peptides to generate neoepitopes that elicit an immune response $(66,67)$. The p-i model holds that the offending drug binds non-covalently to either the TCR or HLA protein to directly activate $\mathrm{T}$ cells without the requirement for antigen processing. This model is thought to explain how some drugs can stimulate T-cell responses in vitro within seconds of drug exposure and/or for IM-ADRs that occur following first exposure to drug $(67,68)$. In IM-ADRs that adhere to the altered peptide repertoire model, the offending drug occupies a position in the peptide binding groove of the HLA protein thereby changing the stereochemistry of the binding cleft and the peptide specificity of HLA binding. It is proposed that peptides presented in this context are recognized as "foreign" by the immune system and therefore elicit a T-cell response. The specificity of the HLA-drug interaction is integral to this model. Currently abacavir hypersensitivity is the only syndrome for which structural, biochemical, and functional evidence exists to support the altered peptide repertoire model. The crystal structure of abacavir bound to HLA-B*57:01 and synthetic or self-peptides has been solved independently by two groups $(69,70)$. It is likely that there are other variations on how drugs non-covalently interact with immune receptors including effects on stability of HLA-peptide or HLA-peptide-TCR complexes or direct binding effects outside of the antigen-binding cleft. It is also possible for HLA class II mediated reactions that drugs or drug metabolites may mediate post-translational peptide modification.

\section{Syndrome-specific effector cells and other considerations}

SJS/TEN is a characterized by profound necrosis localized to the epidermis (Figure 4b). Cytotoxic $\mathrm{CD}^{+}{ }^{+} \mathrm{T}$ cells, NK cells, and NKT cells producing the cytotoxic peptide granulysin, which mediates keratinocyte death, are enriched in blister fluid samples obtained from patients with acute SJS/TEN and are the primary mediators of disease pathogenesis $(59,60,71,72)$. Granulysin serum levels are correlated with the severity of acute disease and mortality $(73,74)$. Studies of HLA-B*15:02-associated carbamazepine-SJS/TEN suggest that the T-cell repertoire in blister fluid is enriched for a single clonotype bearing a common TCR CDR3 sequence and that this appears to be a public clonotype found in the peripheral blood and blister fluid of multiple patients with HLA-B*15:02 associated CBZSJS/TEN (75). A second study did not find such clonotypic restriction in HLA-B*58:01 associated allopurinol-SJS/TEN (76). 
Both $\mathrm{CD} 8^{+}$and $\mathrm{CD} 4^{+}$effector $\mathrm{T}$ cells are thought to be pathogenic mediators in DRESS (Figure $4 \mathrm{~b}$ ). However, unlike SJS/TEN, the immunopathogenesis of DRESS is associated with minimum keratinocyte necrosis, expansion of circulating and skin-infiltrating $\mathrm{CD}^{+}{ }^{+} \mathrm{FoxP} 3^{+} \mathrm{T}$ cells, most likely regulatory $\mathrm{T}$-cells, in the dermis and with reactivation of human herpes viruses such as HHV-6, Epstein-Barr virus, HHV-7, and cytomegalovirus that often coincide with clinical relapse of disease (77-81). It is hypothesized that $\mathrm{CD} 4^{+} \mathrm{FoxP} 3^{+}$ $\mathrm{T}$ cells that home to skin serve to limit the severity of acute disease by regulating the cytotoxic effector T-cell responses (i.e. T-reg). However, it has been observed that Treg responses eventually exhaust following resolution of DRESS and this might contribute to ongoing viral replication and intermittent recurrence of clinical symptoms following resolution that are characteristic of this syndrome $(78,79)$. This model might explain the extended latency period seen in DRESS (2-6 weeks following initiation of drug) and absence of widespread epidermal necrosis that is characteristic of SJS/TEN (79). The role of viral reactivation in the pathogenesis of DRESS is currently unclear. HHV-6 and EBV reactivation have been observed as early as $2-3$ weeks after onset of rash and it has been demonstrated that antiviral $\mathrm{CD} 8^{+}$effector $\mathrm{T}$ cells are expanded during this phase of disease $(78,81)$. Whether the presence of replicating virus contributes to the events inciting DRESS onset or is rather a product of general immune dysfunction such as breakdown of Treg suppressor function has not been defined. It is likely, however, that viral replication and a virus-specific T-cell response does contribute to the clinical features of DRESS including prolonged duration, multi-organ involvement, and relapsing course following withdrawal of glucocorticoid steroids. The presence of autoantibodies and less commonly onset of autoimmune disease such as thyroiditis, systemic lupus, and type I diabetes up to 4 years after resolution of DRESS has been reported in a number of cases and it is possible that ongoing Treg dysfunction contributes to these syndromes as well.

\section{Management}

\section{Drug causality assessment and diagnostics}

Once a diagnosis of SCAR is established based on clinical phenotyping with or without histology and exclusion of relevant differential diagnoses (Table 1), drug causality assessment and immediate withdrawal of the most likely implicated drug(s) is required. A detailed patient history considering all medications must be performed, with the focus on new drugs taken in the 8 weeks prior to presentations. An exposure analysis by a timeline chart is recommended. Common offenders (Figure 2 and Table 2) should be considered initially, but all new drug exposures should be considered and the relevant literature and online sources reviewed for unusual drugs (http://www.drugeruptiondata.com/). An important mistake to avoid is to incorrectly implicate drugs introduced for early symptoms of SCAR, such as antipyretics or antibiotics. Validated drug causality assessment tools help avoid this error; examples include the Naranjo score (82), applied across types of ADRs, or a more tailored tool, such as the algorithm for the assessment of drug causality in SJS/TEN (ALDEN) (83).

In-vivo diagnostics, such as patch or delayed intradermal testing can improve the clinical diagnosis of IM-ADRs, especially in the context of multiple drugs or unclear clinical 
phenotyping (17). They are usually performed once the acute reaction has settled, but within one year. In the case of abacavir patch testing, it was incorporated into large clinical trials to define the phenotype of true immunologically mediated abacavir hypersensitivity and was calculated to have a diagnostic sensitivity of $87 \%$ (84-88). In addition, patch testing (PT) maybe useful to examine for cross-reactivity to similar drugs considered as therapeutic alternatives (89). A large multicentre study examined the utility of patch testing in DRESS, AGEP and SJS/TEN patients within one year of reaction; PT was safe but positive tests varied depending on both drug and clinical phenotype (90).

Amongst HIV-infected patients with TB drug related SJS/TEN, we have described a high incidence of non-life threatening systemic reactions to PT (91). In addition, the negative predictive value of in-vivo drug skin testing for CADRs is only 90\%, depending on the drug tested, making a case for oral provocation challenge if safe and alternative treatments are not available (92). Little impact data are available on how in- vivo testing changes patient management. The situation is similar for in- vitro testing, such as lymphocyte proliferation assays. Research laboratories are using a number of different assays to identify and characterize drug-specific immune cell populations or key cytokines involved in IMADRs, but few of these are utilized for routine diagnostics in the clinic $(93,94)$. There are currently no serum biomarkers when utilized at a single timepoint that allow for early diagnosis or molecular phenotyping in SCAR.

\section{Drug rechallenge}

Currently there is a wide variety of structurally unrelated drugs to treat most conditions making the need for drug rechallenge rarely necessary. However, there are instances when there are no viable alternatives or the alternatives are associated with a higher risk to benefit ratio. Current in-vitro tests like lymphocyte transformation test can be useful, but despite being used for many years, they still exhibit limited sensitivity and specificity that varies with phenotype of CADR and the offending drug $(95,96)$. The options for in-vivo rechallenge include patch tests, skin prick tests, intradermal tests and oral provocation tests. These carry a risk of life threatening rechallenge reactions. Patch tests, skin prick test and intradermal tests theoretically carry a lower risk of a severe reaction due to reduced exposure to the offending drug. However their utility is limited and as a result oral provocation often becomes necessary (96). Oral drug provocation is considered the gold standard in adults and children for identifying the offending drug in suspected drug hypersensitivity (97). Non immediate urticaria and MPE occur frequently in children who are being treated with antibiotic for upper respiratory infections. The rash may be due to the drug, the infection, or the combination. Recent publications have emphasized the safety and effectiveness of oral provocation in children after the resolution of the illness, as the majority of children will tolerate rechallenge without reaction or with only a mild skin reaction (reviewed in Gomes et al 2016 (98)). Diagnostic drug provocation must be distinguished from therapeutic desensitization, or tolerance induction, which is the technique used to induce a state of unresponsiveness to the substance that continues as long as the drug is given (99). Traditional contraindications to drug provocation include pregnancy, significant comorbidities, and SCAR (bullous drug reactions, DRESS, anaphylaxis, systemic vasculitis and drug induced auto-immune disease). It is recommended that drug provocation should 
take place after at least 4 weeks or at least 5 drug elimination cycles have passed since the ADR episode (97). These requirements are not always associated with the best outcomes (97). A good example is tuberculosis-associated SCAR in HIV-infected persons, where all the first-line drugs can be offenders and second-line drugs are less effective and associated with significantly poorer outcomes. Delay in reintroduction of optimal antituberculosis therapy results in higher mortality (25).

Before a rechallenge is undertaken certain conditions have to be met which include the absence of alternative reasonably effective drugs and potential worsening of outcomes if the specific drug(s) is not used. Based on current knowledge and experience, rechallenge in SCAR should be performed in a controlled environment with resuscitation facilities using established protocols (25). There is emerging evidence that oral drug provocation can be safe and feasible, even in life threatening conditions such as SJS/TEN and DRESS, if performed under close observation in hospital (100) (101). However, rechallenge is complex and needs a multidisciplinary team of experienced physicians. There are still many unanswered questions that future studies need to address including dosing schedules, full dose or escalating dose rechallenges, clinical and laboratory features of rechallenge and how soon can rechallenge be safely attempted post SCAR (25).

\section{Genetic screening}

There have been an increasing number of class I and class II HLA associations described with many drugs and SCAR and these have been instrumental in helping us understand the immunopathogenesis of these diseases. These have been comprehensively referenced with respect to T-cell mediated reactions (102) and here we include the highest odds ratio associations of potential clinical interest (Table 3). In addition to HLA risk, some specific drug metabolizing phenotypes have been implicated as important, as seen with the strong association between CYP2C $9 * 3$ poor metabolizing genotypes and phenytoin SCAR (SJS/ TEN>DRESS>maculopapular exanthema) (103) and CYP2B6 poor metabolizing genotypes and nevirapine cutaneous reactions (104). Despite an increasing number of associations genetic screening has been infrequently implemented into routine clinical practice with the notable examples being HLA-B*57:01 screening prior to prescription of the anti-retroviral drug abacavir and HLA-B*15:02 screening before carbamazepine prescription in many Southeast Asian countries where this allele is prevalent. Interestingly, attempts to implement HLA-B*15:02 screening in Hong Kong prior to carbamazepine prescription led to prescription of alternative anti-convulsants even in the case of HLA-B*15:02 negativity. This led to displacement of carbamazepine SJS/TEN by phenytoin SJS/TEN and no change in the overall incidence of SJS/TEN (105). The biggest hurdle for HLA screening for many drugs is the fact that HLA risk is necessary but not sufficient for the development of the hypersensitivity in question. In many cases this translates into an extremely high number of patients that would need to be tested for the HLA risk allele to prevent one case of hypersensitivity. For example, in the case of HLA-B*57:01 and flucloxacillin associated hepatitis almost 14,000 would need to be screened to prevent one case of hepatitis. Implementation of HLA-B*57:01 screening into clinical practice for abacavir hypersensitivity has been highly successful for several reasons including: 1) few patients had to be tested to prevent one case (Table 3) therefore clinicians with high practice volumes 
could quickly and realiably test its effectiveness; 2) HIV treating physicians were a narrow constituency who had ownership of the drug; 3) True abacavir hypersensitivity occurred early (within 3 weeks of starting the drug); 4) Testing had 100\% negatives predictive value and a comparatively high positive predictive value (55\%), therefore if no HLA-B*57:01, no hypersensitivity; 5) Early availability of cost-effective, reliable laboratory tests (single allele testing) with quick turn-around-times; 6) Early engagement of academic and industry champions.

\section{Prognosis}

Mortality rates from a large cohort of SJS/TEN were 23\% at six weeks, $28 \%$ at three months, and $34 \%$ at one year. Patients with TEN, the more extensive variant have mortality close to 50\% (34). SCORe of Toxic Epidermal Necrosis (SCORTEN) is a validated severityof-illness score for SJS/TEN in the first day of admission. Seven clinical variables included in SCORTEN are: age more than 40 years, malignancy, heart rate $>120 /$ minute, initial epidermal detachment $>10 \%$ of BSA, serum urea level $>28 \mathrm{mgm} / \mathrm{dl}$, serum glucose levels $>250 \mathrm{mgm} / \mathrm{dl}$ and serum bicarbonate levels $<20 \mathrm{mEq} / \mathrm{dl}$. Each variable is allocated a single point and the score is a sum of these. The predicted probability of death is as follows: $0-1$ points $-3 \% ; 2$ points $-12 \% ; 3$ points $-35 \% ; 4$ points $-58 \% ; 5$ to 7 points $-90 \%$ (106). Prompt withdrawal of the offending agent can reduce mortality by $\sim 30 \%$ (34). On the other hand, mortality rates for DRESS is estimated at $10 \%$, but recent studies suggest lower rates. Common causes of DRESS-associated mortality include liver failure or secondary infection. Predictors of poor outcomes in DRESS have not been established (18). Mortality rates associated with AGEP are difficult to ascertain, but are estimated at less than 5\% (11).

\section{Biomarkers}

An ideal biomarker should be easily accessible, affordable and suitable for the early diagnosis of a disease in routine screening or at the first sign of symptoms. It should also vary with disease progression or regression within an individual. Current biomarkers for CADR are far from ideal. Potential markers that have been identified include: eosinophilia, granulysin, perforin, IFN- $\gamma$, soluble FAS ligand and CD69 $(107,108)(109,110)$. Some authors have suggested that combining different assays to measure different biomarkers yields better sensitivity and specificity (95). It also implies higher overall costs. Unlike genetic screening, biomarkers for CADR have not yet been validated for routine clinical use.

\section{Supportive and specific therapies for SCAR}

Management of drug hypersensitivity reactions relies upon prompt diagnosis, removal of the offending drug(s) and early appropriate management $(57,111)$. Management varies with the type of CADR.

\section{Drug exanthems, serum sickness-like reaction and fixed drug eruptions}

These are usually mild diseases and a majority of cases resolve without any intervention. In cases with mild fever and a significant rash, topical steroids and supportive care are indicated. The latter may include oral antihistamines and analgesics for fever. In cases of mild to moderate rash without fever, hepatitis (or other internal organ involvement) and 
without mucosal involvement it may be reasonable to continue the drug with symptomatic management if chronic or prolonged treatment is deemed necessary as the rash will remit in most cases. Oral steroids are rarely indicated (112). There are also desensitisation protocols for certain common drugs e.g. cotrimoazole and allopurinol that can be used successfully in the setting of mild to moderate MPE, and in the case of cotrimoxazole for prophylaxis in patients living with HIV/AIDS even in SCAR. A Cochrane review found no severe recurrence of SCAR using both dose escalation and full dose rechallenge for co-trimoxazole in HIV-infected persons, but beneficial effect of using desensitization over rechallenge at six months of follow-up for preventing discontinuation of co-trimoxazole, and for lower incidence of overall hypersensitivity (113). Two types of desensitization protocols have been suggested for allopurinol, slower ones ranging from 16 to 28 days and a shorter one over 5 days. The slower protocols are associated with better outcomes (114).

SJS/TEN-Supportive care is critical in the management of SJS/TEN. These patients should be managed in an appropriate hospital setting, based on SCORTEN (106). This is frequently in intensive care units or burn units. A team approach which includes dermatologists, burns unit specialists, ICU specialists, nutritionists, ophthalmologists, microbiologists, infectious disease specialists, general physicians and pain management team centered around a core of good nurses assures optimal management. Adequate nutrition with diet and fluid modification to offset severe dysphagia and odynophagia is critical. Fluid diet is preferable taking into consideration the temperature, acidity, texture and moisture of feeds. Oral feeding helps prevent adhesions in the upper oesophagus. Careful protection of the exposed dermis and early reepithelialising skin prevents further detachment and use clean, sterile, non-adhesive dressings. There is limited data on pain management in SJS/TEN and currently the closest protocols are those used for burn pain management. These cater for both the background low intensity pain and the more intense procedural pain. Oral trans-mucosal short-acting medium potency opioids are best for procedural pain. Lowdose benzodiazepines, longer-acting, mild to moderate potency opioids together with paracetamol should be given for background pain (115). Frequent monitoring of vital signs is an important part of management to detect first signs of systemic infections. Based on current literature there is no role for prophylactic antibiotics. Temperature control and fluid balance also need to be considered. The use of adjunctive immunomodulatory therapies in SJS/TEN is controversial. The benefits of systemic steroids and intravenous immunoglobulins, although used routinely in some centres, is not fully supported by current evidence. In the case of intravenous immune globulin in particular this may relate to the lateness of presentation of most patients with drug-induced SJS/TEN and loss of an earlier window period where this treatment may have been effective. Other immunosuppressive drugs like cyclosporine, have been reported with mixed results or limited benefit that still need further studies in larger populations (116). Prevention of long-term eye complications is critical in the management of SJS/TEN. General supportive care with frequent lubrication and early assessment by an ophthalmologist to prevent or manage these complications is indicated. Prevention of adhesions and subsequent fibrosis in the genital mucosa entails frequent lubrication and frequent separation of these surfaces (117). The long-term sequelae and follow-up requirements for patients with SJS/TEN are outlined in Table 4. 
DRESS—Patients with suspected DRESS syndrome should be hospitalized until the inflammatory parameters and systemic disability are resolved. A clear threshold to initiate systemic versus topical therapy has not been established and expert practice differs. Depending on the severity, when the diagnosis of DRESS is made, systemic corticosteroids are frequently prescribed, either oral or parenteral. Systemic steroids are generally recommended in settings of life-threatening inflammation with internal organ involvement, irrespective of viral reactivation. However, in milder cases with associated co-morbidities like advanced HIV and TB co-infection, potent topical steroids are preferable (118). Similar to SJS/TEN, the use of systemic immunomodulatory treatments such as high-dose intravenous immunoglobulin have been used in DRESS with case reports of success (119), Caution should be exerted given the lack of evidence supporting this practice and at least one intravenous immunoglobulin DRESS treatment study that was terminated early because of lack of benefit, need for rescue corticosteroid treatment, and severe ADRs in 5/6 patients. This included one patient with pulmonary embolism at day 9 which is a described ADR associated with intravenous immunoglobulin, particularly in the setting of underlying autoimmune disease $(120,121)$. In cases of internal organ failure, organ specific treatment and supportive care should be initiated. Long-term follow up is required to manage autoimmune sequelae (122) (Table 4).

\section{SCAR in pregnancy}

Pregnant women in the context of ADRs are a unique subset as the reaction not only impacts on the mother but the unborn baby. The critical questions are whether pregnancy predisposes to SCAR, does SCAR impact the fetus directly as well as the outcomes of the current pregnancy and subsequent pregnancies. Almost all of the published data, mainly case reports, has been on SJS/TEN. It is not clear if pregnancy itself predisposes the mother to SCAR although one small study in South Africa suggested that pregnancy is a risk factor for SJS in HIV-infected women taking nevirapine (123). There are a handful of published reports of maternal SJS/TEN affecting the unborn fetus (124). In the largest study published to date assessing pregnancy outcomes in 22 pregnant women in South Africa, none of the fetuses developed SJS/TEN. In this study, examined placentas were normal clinically and histologically and the placenta to birth weight ratio, a predictor of pregnancy outcomes, was normal. The study concluded that maternal and fetal mortality was not increased and fetal manifestation of SJS/TEN was not the norm (125). However, other studies have suggested that TEN, the more severe form of the disease is associated with a higher risk of premature labor (126).

Fibrosis and scarring of the birth canal is not an infrequent finding in SJS/TEN and there are several reports confirming that it interferes with normal vaginal delivery in some cases. It has been suggested that a careful assessment of the birth canal pre-delivery is undertaken and even if the canal is assessed as adequate for normal vaginal delivery, the obstetricians should still prepare for a caesarian section and fetal resuscitation (126). 


\section{Conclusion}

Clinicians involved in the assessment and management of CADRs need to have a good understanding of the clinical features of the more uncommon SCAR reactions that are associated with significant morbidity and mortality. Despite substantial advances in our understanding of the immunopathogenesis of these delayed IM-ADRs, diagnosis and management continues to rely heavily on clinical case definitions and causality assessments supported by histology and laboratory parameters. In some instances drug specific ex vivolin vitro and in vivo diagnostics are useful but are not are not widely available. Drug provocation testing, where benefit outweighs risks, is often the only definitive method to able to identify offending agent(s) amongst polypharmacy. Genetic screening has reached clinical practice for certain specific offending drugs and SCAR sub-types with $100 \%$ negative predictive value of testing in some cases. However, in many instances large numbers needed to test to prevent one case which is driven by low disease prevalence, low positive predictive values and cost make implementation impractical. Many aspects of IMADRs require further research including: i) ongoing mechanistic insights into immunopathogeneis, ii) improved diagnostic tests, iii) biomarkers for prognosis and to guide treatment e.g. when to initiate systemic corticosteroids or other immunomodulatory therapies, and iv) novel therapies that can alter morbidity and mortality.

\section{Acknowledgments}

We would like to acknowledge the work of Karen Adamson, Freelance graphics designed, Cape Town South Africa who helped with figures illustrations.

Funding support: EP, KW and KK are supported the National Institutes of Health (1P50GM115305-01); EP is additionally supported through 1R01AI103348-01, 1P30AI110527-01A1, The National Health \& Medical Research Association (Australia) and Australian Centre for HIV \& Hepatitis Research (ACH2)

EP is funded by the NIH (1P50GM115305-01, 1RO1A1103348-01,1P30AI110257-01A1) and the NHMRC (Australia) and Australian Centre for HIV and Hepatitis Virology Research

KW is funded by 1P50GM115305-01

KK is funded by T32GM007347

\section{Abbreviations}
ADR Adverse drug reaction
IM-ADR Immune-mediated adverse drug reactions
CADR Cutaneous adverse drug reaction
SCAR Severe cutaneous adverse reaction
SJS Stevens-Johnson syndrome
TEN Toxic epidermal necrolysis
DRESS Drug reaction, eosinophilia and systemic syndrome
DIHS Drug induced hypersensitivity syndrome 


$\begin{array}{ll}\text { AGEP } & \text { Acute generalised exanthematous pustulosis } \\ \text { FDE } & \text { Fixed drug eruption } \\ \text { GBFDE } & \text { Generalised bullous fixed drug eruption } \\ \text { LDR } & \text { Lichenoid drug reaction } \\ \text { SS } & \text { Serum sickness } \\ \text { SSLR } & \text { Serum sickness like reaction } \\ \text { HIV } & \text { Human immunodeficiency virus } \\ \text { TB } & \text { Tuberculosis } \\ \text { HLA } & \text { Human leucocyte antigen } \\ \text { MPE } & \text { Maculapapular exanthem }\end{array}$

\section{References}

1. Kinch MS, Haynesworth A, Kinch SL, Hoyer D. An overview of FDA-approved new molecular entities: 1827-2013. Drug discovery today. 2014; 19(8):1033-9. [PubMed: 24680947]

2. Kongkaew C, Noyce PR, Ashcroft DM. Hospital admissions associated with adverse drug reactions: a systematic review of prospective observational studies. The Annals of pharmacotherapy. 2008; 42(7):1017-25. [PubMed: 18594048]

3. Smyth RMD, Gargon E, Kirkham J, Cresswell L, Golder S, Smyth R, et al. Adverse drug reactions in children - a systematic review. PloS one. 2012; 7(3):e24061-e. [PubMed: 22403604]

4. Mockenhaupt M. Epidemiology of cutaneous adverse drug reactions. Chemical immunology and allergy. 2012; 97:1-17. [PubMed: 22613850]

5. Huang HY, Luo XQ, Chan LS, Cao ZH, Sun XF, Xu JH. Cutaneous adverse drug reactions in a hospital-based Chinese population. Clinical and experimental dermatology. 2011; 36(2):135-41. [PubMed: 20738322]

6. Eluwa GI, Badru T, Agu KA, Akpoigbe KJ, Chabikuli O, Hamelmann C. Adverse drug reactions to antiretroviral therapy (ARVs): incidence, type and risk factors in Nigeria. BMC clinical pharmacology. 2012; 12:7. [PubMed: 22369677]

7. Coopman SA, Johnson RA, Platt R, Stern RS. Cutaneous disease and drug reactions in HIV infection. N Engl J Med. 1993; 328(23):1670-4. [PubMed: 8487826]

8. Sun J, Liu J, Gong QL, Ding GZ, Ma LW, Zhang LC, et al. Stevens-Johnson Syndrome and toxic epidermal necrolysis: a multi-aspect comparative 7-year study from the People's Republic of China. Drug design, development and therapy. 2014; 8:2539-47.

9. Su P, Aw CW. Severe cutaneous adverse reactions in a local hospital setting: a 5-year retrospective study. International journal of dermatology. 2014; 53(11):1339-45. [PubMed: 25070588]

10. Lehloenya RJ, Kgokolo M. Clinical presentations of severe cutaneous drug reactions in HIVinfected Africans. Dermatologic clinics. 2014; 32(2):227-35. [PubMed: 24680008]

11. Dodiuk-Gad RP, Laws PM, Shear NH. Epidemiology of severe drug hypersensitivity. Seminars in cutaneous medicine and surgery. 2014; 33(1):2-9. [PubMed: 25037253]

12. Patel TK, Barvaliya MJ, Sharma D, Tripathi C. A systematic review of the drug-induced StevensJohnson syndrome and toxic epidermal necrolysis in Indian population. Indian journal of dermatology, venereology and leprology. 2013; 79(3):389-98.

13. Ding WY, Lee CK, Choon SE. Cutaneous adverse drug reactions seen in a tertiary hospital in Johor, Malaysia. International journal of dermatology. 2010; 49(7):834-41. [PubMed: 20618508] 
14. Li LF, Ma C. Epidemiological study of severe cutaneous adverse drug reactions in a city district of China. Clinical and experimental dermatology. 2006; 31(5):642-7. [PubMed: 16901302]

15. Mockenhaupt M, Viboud C, Dunant A, Naldi L, Halevy S, Bouwes Bavinck JN, et al. StevensJohnson syndrome and toxic epidermal necrolysis: assessment of medication risks with emphasis on recently marketed drugs. The EuroSCAR-study. The Journal of investigative dermatology. 2008; 128(1):35-44. [PubMed: 17805350]

16. Mittmann N, Knowles SR, Koo M, Shear NH, Rachlis A, Rourke SB. Incidence of toxic epidermal necrolysis and Stevens-Johnson Syndrome in an HIV cohort: an observational, retrospective case series study. American journal of clinical dermatology. 2012; 13(1):49-54. [PubMed: 22145749]

17. Pavlos R, Mallal S, Ostrov D, Pompeu Y, Phillips E. Fever, rash, and systemic symptoms: understanding the role of virus and HLA in severe cutaneous drug allergy. The journal of allergy and clinical immunology In practice. 2014; 2(1):21-33. [PubMed: 24565765]

18. Cacoub P, Musette P, Descamps V, Meyer O, Speirs C, Finzi L, et al. The DRESS syndrome: a literature review. The American journal of medicine. 2011; 124(7):588-97. [PubMed: 21592453]

19. Sidoroff A, Dunant A, Viboud C, Halevy S, Bavinck JN, Naldi L, et al. Risk factors for acute generalized exanthematous pustulosis (AGEP)-results of a multinational case-control study (EuroSCAR). The British journal of dermatology. 2007; 157(5):989-96. [PubMed: 17854366]

20. Lipowicz S, Sekula P, Ingen-Housz-Oro S, Liss Y, Sassolas B, Dunant A, et al. Prognosis of generalized bullous fixed drug eruption: comparison with Stevens-Johnson syndrome and toxic epidermal necrolysis. The British journal of dermatology. 2013; 168(4):726-32. [PubMed: 23413807]

21. Brahimi N, Routier E, Raison-Peyron N, Tronquoy AF, Pouget-Jasson C, Amarger S, et al. A three-year-analysis of fixed drug eruptions in hospital settings in France. European journal of dermatology : EJD. 2010; 20(4):461-4. [PubMed: 20507840]

22. Ramasamy SN, Korb-Wells CS, Kannangara DR, Smith MW, Wang N, Roberts DM, et al. Allopurinol hypersensitivity: a systematic review of all published cases, 1950-2012. Drug safety. 2013; 36(10):953-80. [PubMed: 23873481]

23. Halevy S, Ghislain PD, Mockenhaupt M, Fagot JP, Bouwes Bavinck JN, Sidoroff A, et al. Allopurinol is the most common cause of Stevens-Johnson syndrome and toxic epidermal necrolysis in Europe and Israel. Journal of the American Academy of Dermatology. 2008; 58(1): 25-32. [PubMed: 17919772]

24. Aceti A, Gianserra L, Lambiase L, Pennica A, Teti E. Pharmacogenetics as a tool to tailor antiretroviral therapy: A review. World journal of virology. 2015; 4(3):198-208. [PubMed: 26279982]

25. Lehloenya RJ, Dheda K. Cutaneous adverse drug reactions to anti-tuberculosis drugs: state of the art and into the future. Expert Rev Anti Infect Ther. 2012; 10(4):475-86. [PubMed: 22512756]

26. Rosen AC, Balagula Y, Raisch DW, Garg V, Nardone B, Larsen N, et al. Life-threatening dermatologic adverse events in oncology. Anti-cancer drugs. 2014; 25(2):225-34. [PubMed: 24108082]

27. Ziemer M, Kardaun SH, Liss Y, Mockenhaupt M. Stevens-Johnson syndrome and toxic epidermal necrolysis in patients with lupus erythematosus: a descriptive study of 17 cases from a national registry and review of the literature. The British journal of dermatology. 2012; 166(3):575-600. [PubMed: 22014091]

28. Mockenhaupt M. The current understanding of Stevens-Johnson syndrome and toxic epidermal necrolysis. Expert review of clinical immunology. 2011; 7(6):803-13. quiz 14-5. [PubMed: 22014021]

29. Bigby M. Rates of cutaneous reactions to drugs. Arch Dermatol. 2001; 137(6):765-70. [PubMed: 11405768]

30. Brauer J, Votava HJ, Meehan S, Soter NA. Lichenoid drug eruption. Dermatol Online J. 2009; 15(8):13.

31. Bastuji-Garin S, Rzany B, Stern RS, Shear NH, Naldi L, Roujeau JC. Clinical classification of cases of toxic epidermal necrolysis, Stevens-Johnson syndrome, and erythema multiforme. Arch Dermatol. 1993; 129(1):92-6. [PubMed: 8420497] 
32. Roujeau JC. Stevens-Johnson syndrome and toxic epidermal necrolysis are severity variants of the same disease which differs from erythema multiforme. J Dermatol. 1997; 24(11):726-9. [PubMed: 9433029]

33. Roujeau JC. The spectrum of Stevens-Johnson syndrome and toxic epidermal necrolysis: a clinical classification. The Journal of investigative dermatology. 1994; 102(6):28S-30S. [PubMed: 8006430]

34. Sekula P, Dunant A, Mockenhaupt M, Naldi L, Bouwes Bavinck JN, Halevy S, et al. Comprehensive survival analysis of a cohort of patients with Stevens-Johnson syndrome and toxic epidermal necrolysis. The Journal of investigative dermatology. 2013; 133(5):1197-204. [PubMed: 23389396]

35. Gomez-Criado MS, Ayani I, Leon-Colombo T, Ramos ML, Reneses MJ. Stevens-Johnson syndrome, toxic epidermal necrolysis and phenytoin. Factors linked to a higher risk. Rev Neurol. 2004; 38(11):1056-60. [PubMed: 15202085]

36. Kardaun SH, Sekula P, Valeyrie-Allanore L, Liss Y, Chu CY, Creamer D, et al. Drug reaction with eosinophilia and systemic symptoms (DRESS): an original multisystem adverse drug reaction. Results from the prospective RegiSCAR study. Br J Dermatol. 2013; 169(5):1071-80. [PubMed: 23855313]

37. Kardaun SH, Sidoroff A, Valeyrie-Allanore L, Halevy S, Davidovici BB, Mockenhaupt M, et al. Variability in the clinical pattern of cutaneous side-effects of drugs with systemic symptoms: does a DRESS syndrome really exist? Br J Dermatol. 2007; 156(3):609-11. [PubMed: 17300272]

38. Cho YT, Lin JW, Chen YC, Chang CY, Hsiao CH, Chung WH, et al. Generalized bullous fixed drug eruption is distinct from Stevens-Johnson syndrome/toxic epidermal necrolysis by immunohistopathological features. J Am Acad Dermatol. 2014; 70(3):539-48. [PubMed: 24388722]

39. Korkij W, Soltani K. Fixed drug eruption. A brief review. Arch Dermatol. 1984; 120(4):520-4. [PubMed: 6231004]

40. Baird BJ, De Villez RL. Widespread bullous fixed drug eruption mimicking toxic epidermal necrolysis. Int J Dermatol. 1988; 27(3):170-4. [PubMed: 3286546]

41. Sidoroff A, Halevy S, Bavinck JN, Vaillant L, Roujeau JC. Acute generalized exanthematous pustulosis (AGEP)--a clinical reaction pattern. J Cutan Pathol. 2001; 28(3):113-9. [PubMed: 11168761]

42. Hotz C, Valeyrie-Allanore L, Haddad C, Bouvresse S, Ortonne N, Duong TA, et al. Systemic involvement of acute generalized exanthematous pustulosis: a retrospective study on 58 patients. The British journal of dermatology. 2013; 169(6):1223-32. [PubMed: 23855377]

43. Roujeau JC, Bioulac-Sage P, Bourseau C, Guillaume JC, Bernard P, Lok C, et al. Acute generalized exanthematous pustulosis. Analysis of 63 cases. Arch Dermatol. 1991; 127(9):1333-8. [PubMed: 1832534]

44. Halevy S, Kardaun SH, Davidovici B, Wechsler J. The spectrum of histopathological features in acute generalized exanthematous pustulosis: a study of 102 cases. The British journal of dermatology. 2010; 163(6):1245-52. [PubMed: 20698849]

45. Apisarnthanarak A, Uyeki TM, Miller ER, Mundy LM. Serum sickness-like reaction associated with inactivated influenza vaccination among Thai health care personnel: risk factors and outcomes. Clin Infect Dis. 2009; 49(1):e18-22. [PubMed: 19480578]

46. Kunnamo I, Kallio P, Pelkonen P, Viander M. Serum-sickness-like disease is a common cause of acute arthritis in children. Acta Paediatr Scand. 1986; 75(6):964-9. [PubMed: 3564980]

47. Zhang FR, Liu H, Irwanto A, Fu XA, Li Y, Yu GQ, et al. HLA-B*13:01 and the dapsone hypersensitivity syndrome. N Engl J Med. 2013; 369(17):1620-8. [PubMed: 24152261]

48. Lawley TJ, Bielory L, Gascon P, Yancey KB, Young NS, Frank MM. A prospective clinical and immunologic analysis of patients with serum sickness. N Engl J Med. 1984; 311(22):1407-13. [PubMed: 6387492]

49. Bielory L, Yancey KB, Young NS, Frank MM, Lawley TJ. Cutaneous manifestations of serum sickness in patients receiving antithymocyte globulin. J Am Acad Dermatol. 1985; 13(3):411-7. [PubMed: 3877081] 
50. Zhang Z, Xiang Y, Wang B, Chen H, Cai X, Wang X, et al. Intestinal mucosal permeability of children with cefaclor-associated serum sickness-like reactions. Eur J Pediatr. 2013; 172(4):53743. [PubMed: 23296953]

51. ten Holder SM, Joy MS, Falk RJ. Cutaneous and systemic manifestations of drug-induced vasculitis. Ann Pharmacother. 2002; 36(1):130-47. [PubMed: 11816242]

52. Radić M. Drug-Induced Vasculitis.

53. Mallal S, Nolan D, Witt C, Masel G, Martin AM, Moore C, et al. Association between presence of HLA-B*5701, HLA-DR7, and HLA-DQ3 and hypersensitivity to HIV-1 reverse-transcriptase inhibitor abacavir. Lancet (London, England). 2002; 359(9308):727-32.

54. Hetherington S, Hughes AR, Mosteller M, Shortino D, Baker KL, Spreen W, et al. Genetic variations in HLA-B region and hypersensitivity reactions to abacavir. Lancet (London, England). 2002; 359(9312):1121-2.

55. Hung SI, Chung WH, Liou LB, Chu CC, Lin M, Huang HP, et al. HLA-B*5801 allele as a genetic marker for severe cutaneous adverse reactions caused by allopurinol. Proc Natl Acad Sci U S A. 2005; 102(11):4134-9. [PubMed: 15743917]

56. Chung WH, Hung SI, Hong HS, Hsih MS, Yang LC, Ho HC, et al. Medical genetics: a marker for Stevens-Johnson syndrome. Nature. 2004; 428(6982):486. [PubMed: 15057820]

57. Garcia-Doval I, LeCleach L, Bocquet H, Otero XL, Roujeau JC. Toxic epidermal necrolysis and Stevens-Johnson syndrome: does early withdrawal of causative drugs decrease the risk of death? Arch Dermatol. 2000; 136(3):323-7. [PubMed: 10724193]

58. Leyva L, Torres MJ, Posadas S, Blanca M, Besso G, O'Valle F, et al. Anticonvulsant-induced toxic epidermal necrolysis: monitoring the immunologic response. J Allergy Clin Immunol. 2000; 105(1 Pt 1):157-65. [PubMed: 10629466]

59. Nassif A, Bensussan A, Boumsell L, Deniaud A, Moslehi H, Wolkenstein P, et al. Toxic epidermal necrolysis: effector cells are drug-specific cytotoxic T cells. The Journal of allergy and clinical immunology. 2004; 114(5):1209-15. [PubMed: 15536433]

60. Nassif A, Bensussan A, Dorothee G, Mami-Chouaib F, Bachot N, Bagot M, et al. Drug specific cytotoxic T-cells in the skin lesions of a patient with toxic epidermal necrolysis. The Journal of investigative dermatology. 2002; 118(4):728-33. [PubMed: 11918724]

61. Schnyder B, Mauri-Hellweg D, Zanni M, Bettens F, Pichler WJ. Direct, MHC-dependent presentation of the drug sulfamethoxazole to human alphabeta T cell clones. J Clin Invest. 1997; 100(1):136-41. [PubMed: 9202065]

62. Chessman D, Kostenko L, Lethborg T, Purcell AW, Williamson NA, Chen Z, et al. Human leukocyte antigen class I-restricted activation of CD8+ T cells provides the immunogenetic basis of a systemic drug hypersensitivity. Immunity. 2008; 28(6):822-32. [PubMed: 18549801]

63. Naisbitt DJ, Farrell J, Wong G, Depta JP, Dodd CC, Hopkins JE, et al. Characterization of drugspecific T cells in lamotrigine hypersensitivity. The Journal of allergy and clinical immunology. 2003; 111(6):1393-403. [PubMed: 12789244]

64. Wei CY, Ko TM, Shen CY, Chen YT. A recent update of pharmacogenomics in drug-induced severe skin reactions. Drug Metab Pharmacokinet. 2012; 27(1):132-41. [PubMed: 22041139]

65. Lucas A, Lucas M, Strhyn A, Keane NM, McKinnon E, Pavlos R, et al. Abacavir-reactive memory T cells are present in drug naive individuals. PLoS One. 2015; 10(2):e0117160. [PubMed: 25674793]

66. Pichler WJ. Deciphering the immune pathomechanism of cutaneous drug reactions. Allergy. 2002; 57(Suppl 72):34-6. [PubMed: 12144552]

67. Pichler WJ. Delayed drug hypersensitivity reactions. Ann Intern Med. 2003; 139(8):683-93. [PubMed: 14568857]

68. Pichler WJ, Beeler A, Keller M, Lerch M, Posadas S, Schmid D, et al. Pharmacological interaction of drugs with immune receptors: the p-i concept. Allergology international : official journal of the Japanese Society of Allergology. 2006; 55(1):17-25. [PubMed: 17075282]

69. Ostrov DA, Grant BJ, Pompeu YA, Sidney J, Harndahl M, Southwood S, et al. Drug hypersensitivity caused by alteration of the MHC-presented self-peptide repertoire. Proc Natl Acad Sci U S A. 2012; 109(25):9959-64. [PubMed: 22645359] 
70. Illing PT, Vivian JP, Dudek NL, Kostenko L, Chen Z, Bharadwaj M, et al. Immune self-reactivity triggered by drug-modified HLA-peptide repertoire. Nature. 2012; 486(7404):554-8. [PubMed: 22722860]

71. Le Cleach L, Delaire S, Boumsell L, Bagot M, Bourgault-Villada I, Bensussan A, et al. Blister fluid $\mathrm{T}$ lymphocytes during toxic epidermal necrolysis are functional cytotoxic cells which express human natural killer (NK) inhibitory receptors. Clin Exp Immunol. 2000; 119(1):225-30. [PubMed: 10606987]

72. Leyva L, Torres MJ, Posadas S, Blanca M, Besso G, O'Valle F, et al. Anticonvulsant-induced toxic epidermal necrolysis: monitoring the immunologic response. The Journal of allergy and clinical immunology. 2000; 105(1 Pt 1):157-65. [PubMed: 10629466]

73. Chung WH, Chang WC, Stocker SL, Juo CG, Graham GG, Lee MH, et al. Insights into the poor prognosis of allopurinol-induced severe cutaneous adverse reactions: the impact of renal insufficiency, high plasma levels of oxypurinol and granulysin. Ann Rheum Dis. 2015; 74(12): 2157-64. [PubMed: 25115449]

74. Chung WH, Hung SI, Yang JY, Su SC, Huang SP, Wei CY, et al. Granulysin is a key mediator for disseminated keratinocyte death in Stevens-Johnson syndrome and toxic epidermal necrolysis. Nature medicine. 2008; 14(12):1343-50.

75. Ko TM, Chung WH, Wei CY, Shih HY, Chen JK, Lin CH, et al. Shared and restricted T-cell receptor use is crucial for carbamazepine-induced Stevens-Johnson syndrome. The Journal of allergy and clinical immunology. 2011; 128(6):1266-76. e11. [PubMed: 21924464]

76. Chung WH, Pan RY, Chu MT, Chin SW, Huang YL, Wang WC, et al. Oxypurinol-Specific T Cells Possess Preferential TCR Clonotypes and Express Granulysin in Allopurinol-Induced Severe Cutaneous Adverse Reactions. The Journal of investigative dermatology. 2015; 135(9):2237-48. [PubMed: 25946710]

77. Morito H, Ogawa K, Fukumoto T, Kobayashi N, Morii T, Kasai T, et al. Increased ratio of FoxP3+ regulatory $\mathrm{T}$ cells/CD3+ $\mathrm{T}$ cells in skin lesions in drug-induced hypersensitivity syndrome/drug rash with eosinophilia and systemic symptoms. Clinical and experimental dermatology. 2014; 39(3):284-91. [PubMed: 24635062]

78. Shiohara T, Ushigome Y, Kano Y, Takahashi R. Crucial Role of Viral Reactivation in the Development of Severe Drug Eruptions: a Comprehensive Review. Clin Rev Allergy Immunol. 2015; 49(2):192-202. [PubMed: 24736996]

79. Takahashi R, Kano Y, Yamazaki Y, Kimishima M, Mizukawa Y, Shiohara T. Defective regulatory T cells in patients with severe drug eruptions: timing of the dysfunction is associated with the pathological phenotype and outcome. J Immunol. 2009; 182(12):8071-9. [PubMed: 19494333]

80. Picard D, Janela B, Descamps V, D'Incan M, Courville P, Jacquot S, et al. Drug reaction with eosinophilia and systemic symptoms (DRESS): a multiorgan antiviral T cell response. Sci Transl Med. 2010; 2(46):46ra62.

81. Shiohara T, Kano Y, Takahashi R, Ishida T, Mizukawa Y. Drug-induced hypersensitivity syndrome: recent advances in the diagnosis, pathogenesis and management. Chemical immunology and allergy. 2012; 97:122-38. [PubMed: 22613858]

82. Naranjo CA, Busto U, Sellers EM, Sandor P, Ruiz I, Roberts EA, et al. A method for estimating the probability of adverse drug reactions. Clin Pharmacol Ther. 1981; 30(2):239-45. [PubMed: 7249508]

83. Sassolas B, Haddad C, Mockenhaupt M, Dunant A, Liss Y, Bork K, et al. ALDEN, an algorithm for assessment of drug causality in Stevens-Johnson Syndrome and toxic epidermal necrolysis: comparison with case-control analysis. Clin Pharmacol Ther. 2010; 88(1):60-8. [PubMed: 20375998]

84. Saag M, Balu R, Phillips E, Brachman P, Martorell C, Burman W, et al. High sensitivity of human leukocyte antigen-b*5701 as a marker for immunologically confirmed abacavir hypersensitivity in white and black patients. Clinical infectious diseases : an official publication of the Infectious Diseases Society of America. 2008; 46(7):1111-8. [PubMed: 18444831]

85. Mallal S, Phillips E, Carosi G, Molina JM, Workman C, Tomazic J, et al. HLA-B*5701 screening for hypersensitivity to abacavir. N Engl J Med. 2008; 358(6):568-79. [PubMed: 18256392] 
86. Shear NH, Milpied B, Bruynzeel DP, Phillips EJ. A review of drug patch testing and implications for HIV clinicians. AIDS (London, England). 2008; 22(9):999-1007.

87. Phillips EJ, Sullivan JR, Knowles SR, Shear NH. Utility of patch testing in patients with hypersensitivity syndromes associated with abacavir. AIDS (London, England). 2002; 16(16): 2223-5.

88. Phillips EJ, Wong GA, Kaul R, Shahabi K, Nolan DA, Knowles SR, et al. Clinical and immunogenetic correlates of abacavir hypersensitivity. AIDS (London, England). 2005; 19(9): 979-81.

89. Lin YT, Chang YC, Hui RC, Yang CH, Ho HC, Hung SI, et al. A patch testing and cross-sensitivity study of carbamazepine-induced severe cutaneous adverse drug reactions. J Eur Acad Dermatol Venereol. 2013; 27(3):356-64. [PubMed: 22211830]

90. Barbaud A, Collet E, Milpied B, Assier H, Staumont D, Avenel-Audran M, et al. A multicentre study to determine the value and safety of drug patch tests for the three main classes of severe cutaneous adverse drug reactions. The British journal of dermatology. 2013; 168(3):555-62. [PubMed: 23136927]

91. Lehloenya RJ, Todd G, Wallace J, Ngwanya MR, Muloiwa R, Dheda K. Diagnostic patch testing following tuberculosis-associated cutaneous adverse drug reactions induces systemic reactions in HIV-infected persons. The British journal of dermatology. 2016; 175(1):150-6. [PubMed: 26918554]

92. Waton J, Trechot P, Loss-Ayav C, Schmutz JL, Barbaud A. Negative predictive value of drug skin tests in investigating cutaneous adverse drug reactions. The British journal of dermatology. 2009; 160(4):786-94. [PubMed: 19120340]

93. Rive CM, Bourke J, Phillips EJ. Testing for drug hypersensitivity syndromes. Clin Biochem Rev. 2013; 34(1):15-38. [PubMed: 23592889]

94. Keane NM, Pavlos RK, McKinnon E, Lucas A, Rive C, Blyth CC, et al. HLA Class I restricted CD8+ and Class II restricted CD4+ T cells are implicated in the pathogenesis of nevirapine hypersensitivity. AIDS (London, England). 2014; 28(13):1891-901.

95. Porebski G, Pecaric-Petkovic T, Groux-Keller M, Bosak M, Kawabata TT, Pichler WJ. In vitro drug causality assessment in Stevens-Johnson syndrome - alternatives for lymphocyte transformation test. Clin Exp Allergy. 2013; 43(9):1027-37. [PubMed: 23957338]

96. Bernstein IL, Li JT, Bernstein DI, Hamilton R, Spector SL, Tan R, et al. Allergy diagnostic testing: an updated practice parameter. Ann Allergy Asthma Immunol. 2008; 100(3 Suppl 3):S1-148.

97. Aberer W, Bircher A, Romano A, Blanca M, Campi P, Fernandez J, et al. Drug provocation testing in the diagnosis of drug hypersensitivity reactions: general considerations. Allergy. 2003; 58(9): 854-63. [PubMed: 12911412]

98. Gomes ER, Brockow K, Kuyucu S, Saretta F, Mori F, Blanca-Lopez N, et al. Drug hypersensitivity in children: report from the pediatric task force of the EAACI Drug Allergy Interest Group. Allergy. 2016; 71(2):149-61. [PubMed: 26416157]

99. Todd G. Adverse cutaneous drug eruptions and HIV: a clinician's global perspective. Dermatologic clinics. 2006; 24(4):459-72. vi. [PubMed: 17010776]

100. Lehloenya RJ, Todd G, Badri M, Dheda K. Outcomes of reintroducing anti-tuberculosis drugs following cutaneous adverse drug reactions. The international journal of tuberculosis and lung disease : the official journal of the International Union against Tuberculosis and Lung Disease. 2011; 15(12):1649-57.

101. Lehloenya RJ, Todd G, Wallace J, Ngwanya MR, Muloiwa R, Dheda K. Diagnostic patch testing following tuberculosis-associated cutaneous adverse drug events induces systemic reactions in HIV-infected persons. The British journal of dermatology. 2016

102. White KD, Chung WH, Hung SI, Mallal S, Phillips EJ. Evolving models of the immunopathogenesis of T cell-mediated drug allergy: The role of host, pathogens, and drug response. The Journal of allergy and clinical immunology. 2015; 136(2):219-34. quiz 35. [PubMed: 26254049]

103. Chung WH, Chang WC, Lee YS, Wu YY, Yang CH, Ho HC, et al. Genetic variants associated with phenytoin-related severe cutaneous adverse reactions. Jama. 2014; 312(5):525-34. [PubMed: 25096692] 
104. Yuan J, Guo S, Hall D, Cammett AM, Jayadev S, Distel M, et al. Toxicogenomics of nevirapineassociated cutaneous and hepatic adverse events among populations of African, Asian, and European descent. AIDS (London, England). 2011; 25(10):1271-80.

105. Chen Z, Liew D, Kwan P. Effects of a HLA-B*15:02 screening policy on antiepileptic drug use and severe skin reactions. Neurology. 2014; 83(22):2077-84. [PubMed: 25355835]

106. Bastuji-Garin S, Fouchard N, Bertocchi M, Roujeau JC, Revuz J, Wolkenstein P. SCORTEN: a severity-of-illness score for toxic epidermal necrolysis. The Journal of investigative dermatology. 2000; 115(2):149-53. [PubMed: 10951229]

107. Yang C, Mosam A, Mankahla A, Dlova N, Saavedra A. HIV infection predisposes skin to toxic epidermal necrolysis via depletion of skin-directed CD4(+) T cells. Journal of the American Academy of Dermatology. 2014; 70(6):1096-102. [PubMed: 24629995]

108. Zawodniak A, Lochmatter P, Yerly D, Kawabata T, Lerch M, Yawalkar N, et al. In vitro detection of cytotoxic T and NK cells in peripheral blood of patients with various drug-induced skin diseases. Allergy. 2010; 65(3):376-84. [PubMed: 19793058]

109. Chung WH, Hung SI. Genetic markers and danger signals in stevens-johnson syndrome and toxic epidermal necrolysis. Allergol Int. 2010; 59(4):325-32. [PubMed: 20962567]

110. Beeler A, Zaccaria L, Kawabata T, Gerber BO, Pichler WJ. CD69 upregulation on T cells as an in vitro marker for delayed-type drug hypersensitivity. Allergy. 2008; 63(2):181-8. [PubMed: 18005225]

111. McGee T, Munster A. Toxic epidermal necrolysis syndrome: mortality rate reduced with early referral to regional burn center. Plast Reconstr Surg. 1998; 102(4):1018-22. [PubMed: 9734418]

112. Nigen S, Knowles SR, Shear NH. Drug eruptions: approaching the diagnosis of drug-induced skin diseases. J Drugs Dermatol. 2003; 2(3):278-99. [PubMed: 12848112]

113. Lin D, Li WK, Rieder MJ. Cotrimoxazole for prophylaxis or treatment of opportunistic infections of HIV/AIDS in patients with previous history of hypersensitivity to cotrimoxazole. The Cochrane database of systematic reviews. 2007; (2):CD005646. [PubMed: 17443608]

114. Soares J, Caiado J, Lopes A, Pereira BM. Allopurinol Desensitization: A Fast or Slow Protocol? J Investig Allergol Clin Immunol. 2015; 25(4):295-7.

115. Patterson DR, Hofland HW, Espey K, Sharar S. Nursing Committee of the International Society for Burn I. Pain management. Burns. 2004; 30(8):A10-5. [PubMed: 15555783]

116. Lee HY, Fook-Chong S, Koh HY, Thirumoorthy T, Pang SM. Cyclosporine treatment for StevensJohnson syndrome/toxic epidermal necrolysis: Retrospective analysis of a cohort treated in a specialized referral center. Journal of the American Academy of Dermatology. 2016

117. Lehloenya RJ. Management of Stevens Johnson syndrome and toxic epidermal necrolysis. Current Allergy \& Clinical Immunology. 2007; 20(3):124-8.

118. Funck-Brentano E, Duong TA, Bouvresse S, Bagot M, Wolkenstein P, Roujeau JC, et al. Therapeutic management of DRESS: a retrospective study of 38 cases. J Am Acad Dermatol. 2015; 72(2):246-52. [PubMed: 25592341]

119. Galvao VR, Aun MV, Kalil J, Castells M, Giavina-Bianchi P. Clinical and laboratory improvement after intravenous immunoglobulin in drug reaction with eosinophilia and systemic symptoms. The journal of allergy and clinical immunology In practice. 2014; 2(1):107-10. [PubMed: 24565781]

120. Marie I, Maurey G, Herve F, Hellot MF, Levesque H. Intravenous immunoglobulin-associated arterial and venous thrombosis; report of a series and review of the literature. The British journal of dermatology. 2006; 155(4):714-21. [PubMed: 16965420]

121. Joly P, Janela B, Tetart F, Rogez S, Picard D, D'Incan M, et al. Poor benefit/risk balance of intravenous immunoglobulins in DRESS. Archives of dermatology. 2012; 148(4):543-4. [PubMed: 22508885]

122. Walsh SA, Creamer D. Drug reaction with eosinophilia and systemic symptoms (DRESS): a clinical update and review of current thinking. Clin Exp Dermatol. 2011; 36(1):6-11. [PubMed: 21143513]

123. Dube N, Adewusi E, Summers R. Risk of nevirapine-associated Stevens-Johnson syndrome among HIV-infected pregnant women: the Medunsa National Pharmacovigilance Centre, 2007 2012. S Afr Med J. 2013; 103(5):322-5. [PubMed: 23971123] 
124. Rodriguez G, Trent JT, Mirzabeigi M, Zaulyanov L, Bruce J, Vincek V. Toxic epidermal necrolysis in a mother and fetus. Journal of the American Academy of Dermatology. 2006; 55(5 Suppl):S96-8. [PubMed: 17052547]

125. Knight L, Todd G, Muloiwa R, Matjila M, Lehloenya RJ. Stevens Johnson Syndrome and Toxic Epidermal Necrolysis: Maternal and Foetal Outcomes in Twenty-Two Consecutive Pregnant HIV Infected Women. PloS one. 2015; 10(8):e0135501. [PubMed: 26267659]

126. Struck MF, Illert T, Liss Y, Bosbach ID, Reichelt B, Steen M. Toxic epidermal necrolysis in pregnancy: case report and review of the literature. J Burn Care Res. 2010; 31(5):816-21. [PubMed: 20671561]

127. Phillips EJ. Classifying ADRs--does dose matter? British journal of clinical pharmacology. 2016; 81(1):10-2. [PubMed: 26286675]

128. Saito Y, Stamp LK, Caudle KE, Hershfield MS, McDonagh EM, Callaghan JT, et al. Clinical Pharmacogenetics Implementation Consortium (CPIC) guidelines for human leukocyte antigen B (HLA-B) genotype and allopurinol dosing: 2015 update. Clin Pharmacol Ther. 2016; 99(1):36-7. [PubMed: 26094938]

129. Leckband SG, Kelsoe JR, Dunnenberger HM, George AL Jr, Tran E, Berger R, et al. Clinical Pharmacogenetics Implementation Consortium guidelines for HLA-B genotype and carbamazepine dosing. Clin Pharmacol Ther. 2013; 94(3):324-8. [PubMed: 23695185]

130. Yip VL, Alfirevic A, Pirmohamed M. Genetics of immune-mediated adverse drug reactions: a comprehensive and clinical review. Clinical reviews in allergy \& immunology. 2015; 48(2-3): 165-75. [PubMed: 24777842]

131. McCormack M, Alfirevic A, Bourgeois S, Farrell JJ, Kasperaviciute D, Carrington M, et al. HLAA*3101 and carbamazepine-induced hypersensitivity reactions in Europeans. N Engl J Med. 2011; 364(12):1134-43. [PubMed: 21428769]

132. Daly AK, Donaldson PT, Bhatnagar P, Shen Y, Pe'er I, Floratos A, et al. HLA-B*5701 genotype is a major determinant of drug-induced liver injury due to flucloxacillin. Nat Genet. 2009; 41(7): 816-9. [PubMed: 19483685]

133. Pavlos R, Mallal S, Ostrov D, Buus S, Metushi I, Peters B, et al. T cell-mediated hypersensitivity reactions to drugs. Annu Rev Med. 2015; 66:439-54. [PubMed: 25386935]

134. Chen PL, Shih SR, Wang PW, Lin YC, Chu CC, Lin JH, et al. Genetic determinants of antithyroid drug-induced agranulocytosis by human leukocyte antigen genotyping and genome-wide association study. Nat Commun. 2015; 6:7633. [PubMed: 26151496]

135. Cheung CL, Sing CW, Tang CS, Cheng VK, Pirmohamed M, Choi CH, et al. HLA-B*38:02:01 predicts carbimazole/methimazole-induced agranulocytosis. Clin Pharmacol Ther. 2016; 99(5): 555-61. [PubMed: 26599303]

136. Hallberg P, Eriksson N, Ibanez L, Bondon-Guitton E, Kreutz R, Carvajal A, et al. Genetic variants associated with antithyroid drug-induced agranulocytosis: a genome-wide association study in a European population. Lancet Diabetes Endocrinol. 2016; 4(6):507-16. [PubMed: 27157822]

137. Samanci N, Balci N, Alpsoy E. Heterotopic ossification related to toxic epidermal necrolysis in a patient with Behcet's disease. J Dermatol. 2005; 32(6):469-73. [PubMed: 16043922]

138. Kavanagh GM, Page P, Hanna MM. Silicone gel treatment of extensive hypertrophic scarring following toxic epidermal necrolysis. The British journal of dermatology. 1994; 130(4):540-1. [PubMed: 8186128]

139. Sheridan RL, Schulz JT, Ryan CM, Schnitzer JJ, Lawlor D, Driscoll DN, et al. Long-term consequences of toxic epidermal necrolysis in children. Pediatrics. 2002; 109(1):74-8. [PubMed: 11773544]

140. Jullien D, Prevot G, Wolkenstein P, Roujeau JC, Revuz J. Eruptive nevus in the course of Lyell syndrome. Ann Dermatol Venereol. 1995; 122(8):540-2. [PubMed: 8572497]

141. Gueudry J, Roujeau JC, Binaghi M, Soubrane G, Muraine M. Risk factors for the development of ocular complications of Stevens-Johnson syndrome and toxic epidermal necrolysis. Arch Dermatol. 2009; 145(2):157-62. [PubMed: 19221260]

142. Saeed H, Mantagos IS, Chodosh J. Complications of Stevens-Johnson syndrome beyond the eye and skin. Burns. 2016; 42(1):20-7. [PubMed: 25865527] 
143. Gaultier F, Rochefort J, Landru MM, Allanore L, Naveau A, Roujeau JC, et al. Severe and unrecognized dental abnormalities after drug-induced epidermal necrolysis. Arch Dermatol. 2009; 145(11):1332-3. [PubMed: 19917972]

144. Coetzer M, van der Merwe AE, Warren BL. Toxic epidermal necrolysis in a burn patient complicated by acute pancreatitis. Burns. 1998; 24(2):181-3. [PubMed: 9625248]

145. Carter FM, Mitchell CK. Toxic epidermal necrolysis--an unusual cause of colonic perforation. Report of a case. Dis Colon Rectum. 1993; 36(8):773-7. [PubMed: 8348869]

146. Herman TE, Kushner DC, Cleveland RH. Esophageal stricture secondary to drug-induced toxic epidermal necrolysis. Pediatr Radiol. 1984; 14(6):439-40. [PubMed: 6504607]

147. Mashiko T, Minabe T, Oka A, Ohnishi F. A case of microstomia subsequent to toxic epidermal necrolysis surgically treated by simple technique. Plast Reconstr Surg Glob Open. 2013; 1(3):e21. [PubMed: 25289215]

148. Barrera JE, Meyers AD, Hartford EC. Hypopharyngeal stenosis and dysphagia complicating toxic epidermal necrolysis. Arch Otolaryngol Head Neck Surg. 1998; 124(12):1375-6. [PubMed: 9865761]

149. Rowan DM, Jones RW, Oakley A, de Silva H. Vaginal stenosis after toxic epidermal necrolysis. J Low Genit Tract Dis. 2010; 14(4):390-2. [PubMed: 20885170]

150. Jackel R, Fuchs M, Raff T, Wiedemann B. Drug-induced toxic epidermal necrolysis with involvement of the intestinal and respiratory tract. A case report. Anaesthesist. 2002; 51(10):8159. [PubMed: 12395172]

151. Kamada N, Kinoshita K, Togawa Y, Kobayashi T, Matsubara H, Kohno M, et al. Chronic pulmonary complications associated with toxic epidermal necrolysis: report of a severe case with anti-Ro/SS-A and a review of the published work. J Dermatol. 2006; 33(9):616-22. [PubMed: 16958806]

152. Zitha E, Chiliza B, Muloiwa R, Lehloenya R. Incidence of anxiety and depression in a predominantly HIV-infected population with severe adverse drug reactions. Clinical and Translational Allergy. 2014; 4(3):1. [PubMed: 24393277]

153. Sultan SJ, Sameem F, Ashraf M. Drug reaction with eosinophilia and systemic symptoms: manifestations, treatment, and outcome in 17 patients. Int J Dermatol. 2015; 54(5):537-42. [PubMed: 24738653]

154. Ushigome Y, Kano Y, Ishida T, Hirahara K, Shiohara T. Short- and long-term outcomes of 34 patients with drug-induced hypersensitivity syndrome in a single institution. J Am Acad Dermatol. 2013; 68(5):721-8. [PubMed: 23182063]

155. Chen YC, Chang CY, Cho YT, Chiu HC, Chu CY. Long-term sequelae of drug reaction with eosinophilia and systemic symptoms: a retrospective cohort study from Taiwan. J Am Acad Dermatol. 2013; 68(3):459-65. [PubMed: 22959230]

156. Lew TT, Creamer D, Mackenzie J, Walsh SA. Post-traumatic stress disorder following drug reaction with eosinophilia and systemic symptoms. Br J Dermatol. 2015; 172(3):836-7. [PubMed: 25154661]

157. Lehloenya RJ, Todd G, Mogotlane L, Gantsho N, Hlela C, Dheda K. Lichenoid drug reaction to antituberculosis drugs treated through with topical steroids and phototherapy. The Journal of antimicrobial chemotherapy. 2012; 67(10):2535-7. [PubMed: 22687890] 


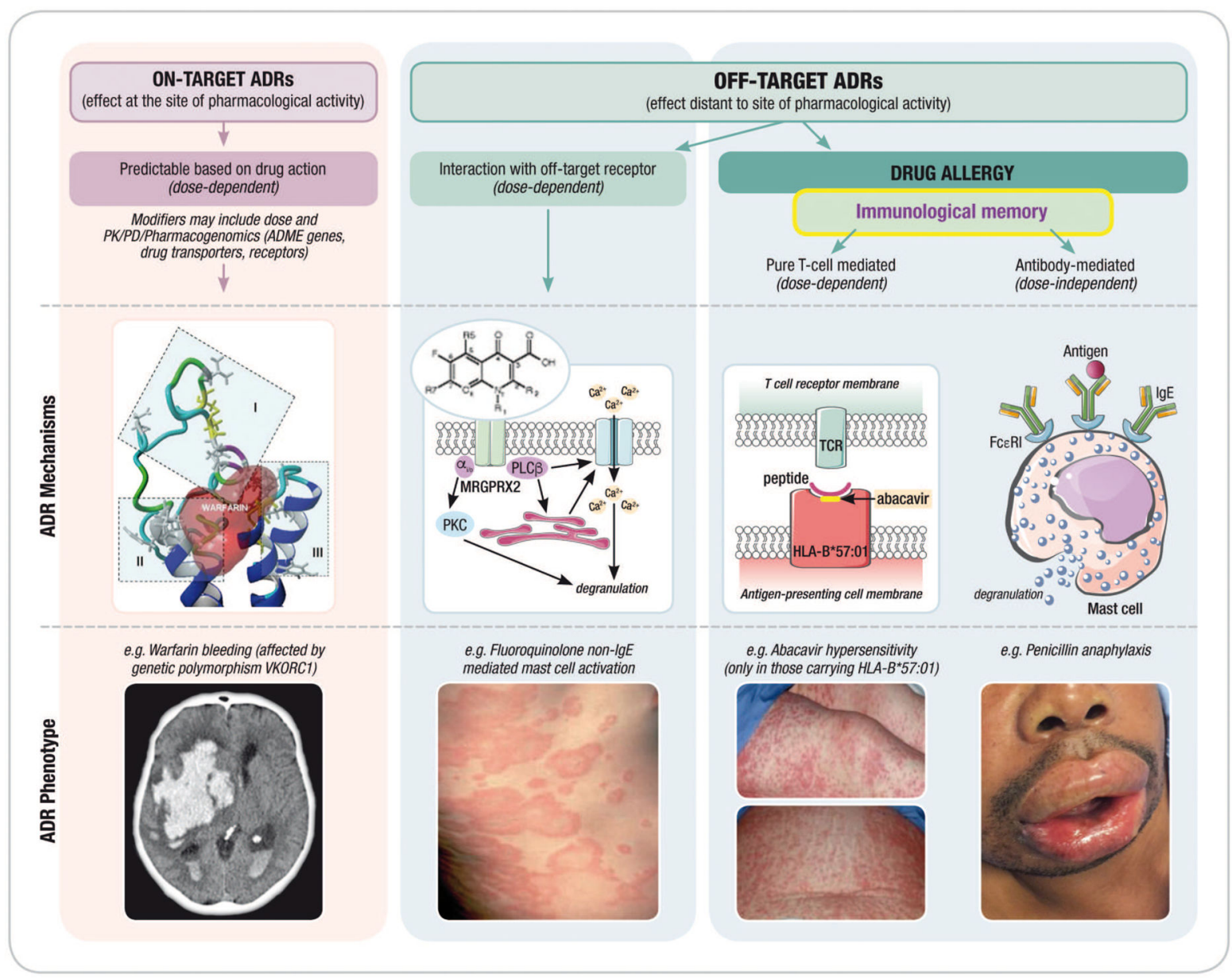

Figure 1. Adverse drug reactions and the immune system

It is proposed that adverse drug reactions are classified according to their on-target vs. offtarget interactions between the drug and cellular components. Both on-target and off-target effects can demonstrate concentration-exposure relationships that may differ between individuals based on acquired or genetic host factors. The interaction between the drug and the target may relate to both the dose and/or duration of treatment. On-target reactions generally relate to an augmentation of the known primary therapeutic and pharmacological action of a drug (eg. bleeding related to warfarin) and off-target effects can occur by mechanisms that are both directly immune mediated and associated with immunological memory of varied duration (drug allergy) and mechanisms without a direct immunological effect and without immunological memory that may have an "immunological phenotype". These reactions are often mediated through a pharmacological interaction (eg. aspirin exacerbated respiratory disease or non-IgE mediated mast-cell activation seen with fluoroquinolones and opioids). Off-target reactions that are non-immunologically mediated are often dose-dependent whereas immunologically-mediated off-target reactions associated with immunological memory can be both dose dependent (T-cell mediated reactions) or dose-independent (recognition and amplification of small amounts of antigen in the case of IgE-mediated reactions). Predisposition to both on-target and off-target reactions is driven 
by genetic variation but also ecological factors that can vary over the course of an individual's lifetime (Adapted from White et al (101) and Phillips (127) 


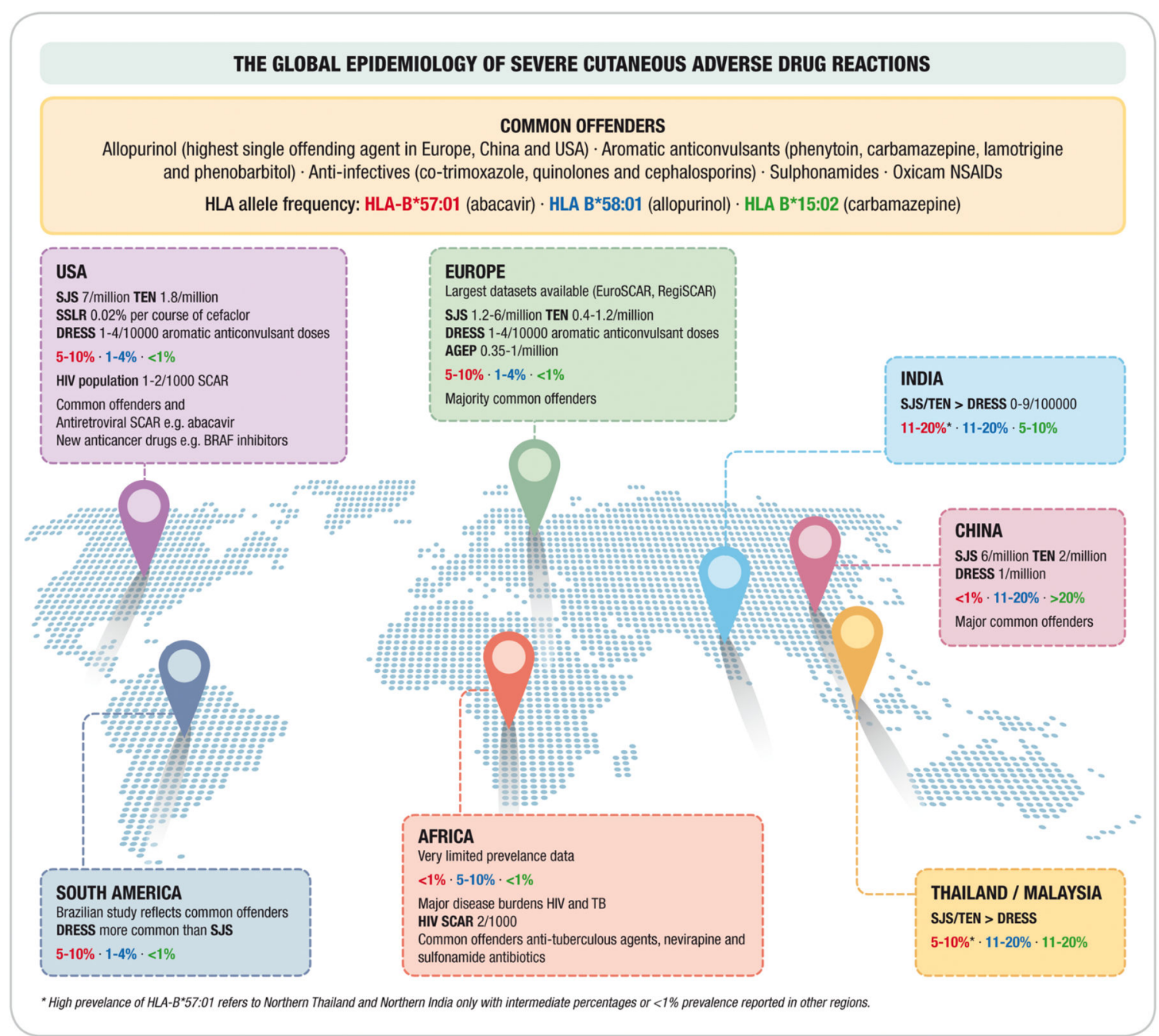

Figure 2. The Global Epidemiology of Severe Cutaneous Adverse Drug Reactions HLA allele frequencies are indicated for different populations and colour coded. If no prevalence figures are provided for a particular phenotype then a relevant continental dataset was not found.

Abbreviations: SJS/TEN, Stevens-Johnson syndrome/toxic epidermal necrolysis; DRESS, drug reaction with eosinophilia and systemic symptoms; AGEP: Acute generalized exanthematous pustulosis; HIV SCAR: Human immunodeficiency related severe cutaneous adverse drug reactions; SSLR: Serum-sickness like reaction; NSAIDs: Non-steroidal antiinflammatory drugs 

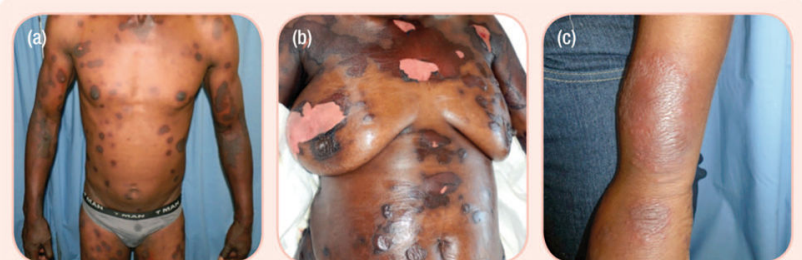

Fixed drug eruption (a) Extensive disease showing pigmented macules, some with blistering (b) bullous variant resembling S.JS and $(c)$ acute fixed drug eruption showing indurated oedematous plaques.
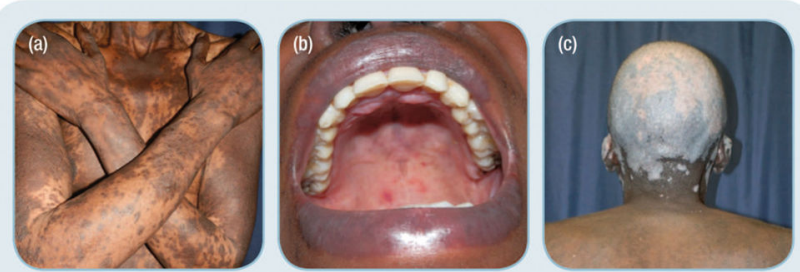

Lichenoid drug reaction (LDR) showing (a) pigmented macules (b) violaceous erythema of the lips and (c) recurrence on re-exposure to the same drug. The depigmented area represents original sequelae of LDR and the violaceous areas developed on re-exposure to the drug.

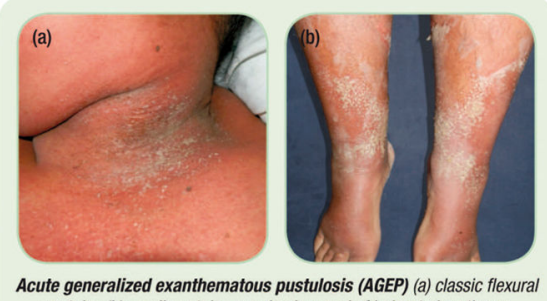
Acute generalized exanthematous pustulosis (AGEP) (a) classic flexu
pustules (b) small pustules on a background of indurated erythema.
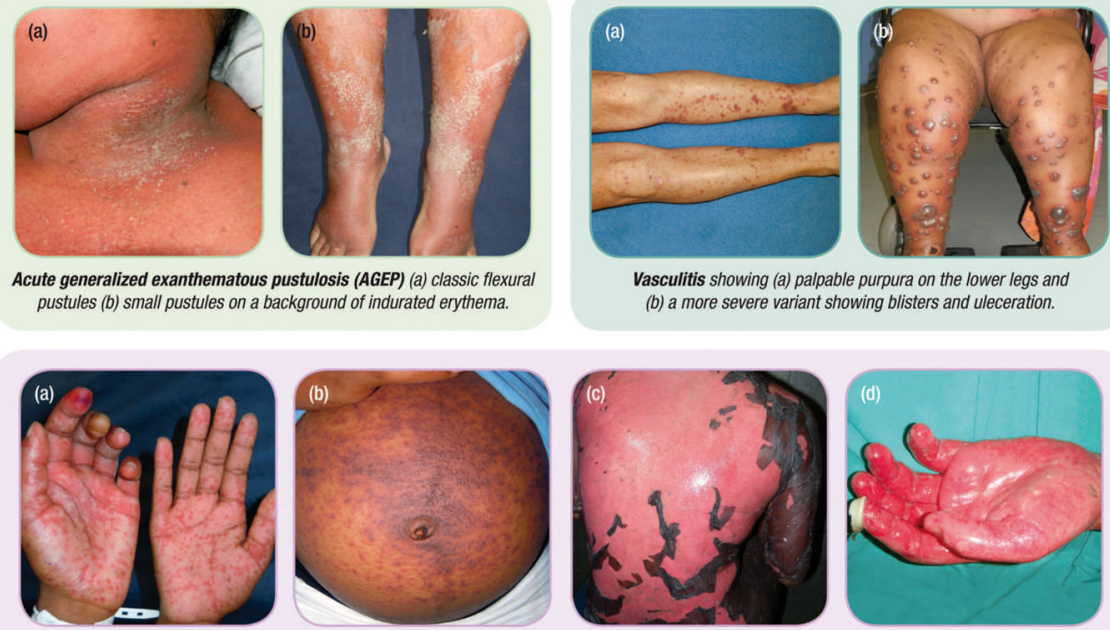

Vasculitis showing (a) palpable purpura on the lower legs and (b) a more severe variant showing blisters and uleceration.

Drug reaction with eosinophilia and systemic symptoms (DRESS) showing (a) exfoliative dermatitis
with severe scaling in a background with severe scaling in a background
of erythema and $(b)$ indurated erythematous macules and papules.

Stevens Johnson syndrome (SJS) and toxic epidermal necrolysis (TEN) (a) focal tender erythematous macules on the palms in SJS (b) focal areas of early epidermal necrosis in a background of erythema in a pregnant woman with SJS (c and d) stripping of the epidermis on the back and palms in TEN.

Figure 3. Montage of images to illustrate important features of different clinical phenotypes 

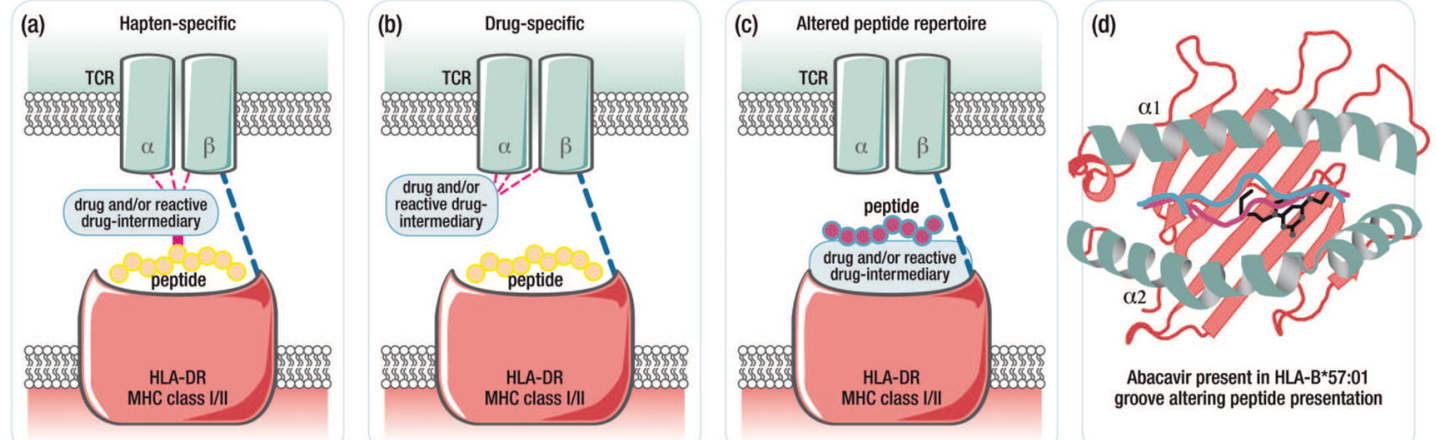

Abacavir present in HLA-B*57:01 groove altering peptide presentation

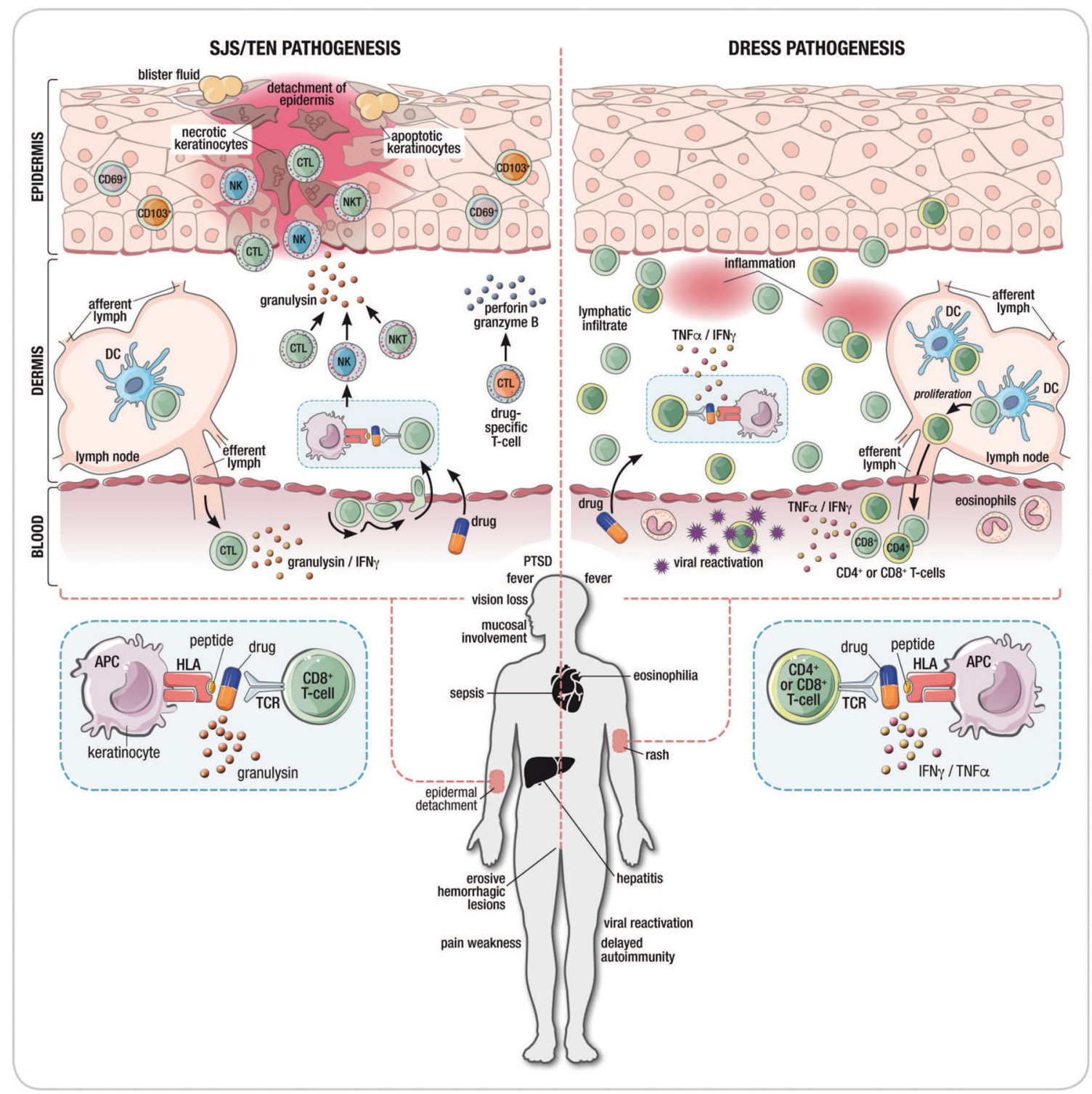

Figure 4. Immunopathogenesis of SCAR

J Allergy Clin Immunol Pract. Author manuscript; available in PMC 2018 May 01. 
Figure 4A: Proposed models of drug hypersensitivity

(a) In the Hapten/prohapten model drugs form covalent bonds with endogenous proteins/ peptides. These drug-modified peptides are then processed by antigen presenting cells and presented on the MHC resuting in a T-cell response. (b) The drug-specific

Pharmacological-Interaction (P-I) model proposed that drug binds directly to immune receptors such as the T-cell Receptor (TCR) or HLA forming non-covalent bonds without the need for peptide. Dashed lines represent non-covalent bonds. (c) The Altered peptide repertoire model the drug forms non-covalent bonds within the binding pocket(s) of the MHC to alter the chemistry of the binding cleft and repertoire of self-peptides able to bind to the HLA molecule in question. Some of these newly presented self-peptides have not been previously tolerized and their presentation results in a T-cell response. (d) The interaction between abacavir and HLA-B*57:01 as occurs in abacavir hypersensitivity syndrome exemplifies the altered peptide repertoire model. Abacavir is shown bound to altered peptide and HLA1014 B*57:01 in the HLA-B*57:01 antigen binding cleft.

Figure 4B. Proposed pathogenic mechanisms in drug-induced Stevens-Johnson syndrome/ toxic epidermal necrolysis (SJS/TEN) and drug reaction with eosinophilia and systemic symptoms (DRESS). The disease process in SJS/TEN occurs in the epidermis. In SJS/TEN, the drug likely interacts with the with human leukocyte antigen protein on keratinocytes which act as antigen-presenting cells to activate drug specific CD8+ cytotoxic $\mathrm{T}$ cells. This interaction causes drug-specific CD8+ T cells to accumulate within epidermal blisters and release perforin and granzyme $\mathrm{B}$ that can kill keratinocytes. Drugs also trigger the activation of CD8+ T cells, NK cells and NKT cells to secrete granulysin which appears to be one of the most important cytotoxic mediators in SJS/TEN and can induce keratinocyte death without the need for cell contact. Clinical symptoms of SJS/TEN include a painful, blistering skin rash that results in epidermal necrosis and detachment as well as less specific symptoms including fever and sepsis. SJS/TEN is associated with a mortality of up to 50\% as well as significant long-term morbidity including permanent corneal scarring, vision loss, prolonged pain and weakness, post-traumatic stress disorder and fear of drug. The dermis is the primary skin compartment involved in DRESS. Both CD8+ and CD4+ T cells are pathogenic mediators in DRESS. DRESS is characterized by a lymphatic infiltrate of $\mathrm{T}$ cells into the dermis and increased release of TNFa and IFN $\gamma$. DRESS is also associated with viral reactivation of human herpesviruses although the role of viral reactivation in DRESS pathogenesis is currently unclear. DRESS presents as a widespread rash of varying severity without skin separation or blistering accompanied by fever, internal organ involvement frequently affecting the liver and eosinophilia. Delayed autoimmune disease can occur as a sequela of DRESS.

Abbreviations: SJS/TEN, Stevens-Johnson syndrome/toxic epidermal necrolysis; DRESS, drug reaction with eosinophilia and systemic symptoms; CTL, cytotoxic lymphocyte; NKT, natural killer T cell; NK, natural killer cell; IFN $\gamma$, interferon-gamma; TNFa, tumor necrosis factor alpha; DC, dendritic cell; APC, antigen-presenting cell; TCR, T-cell receptor; PTSD, post-traumatic stress disorder 


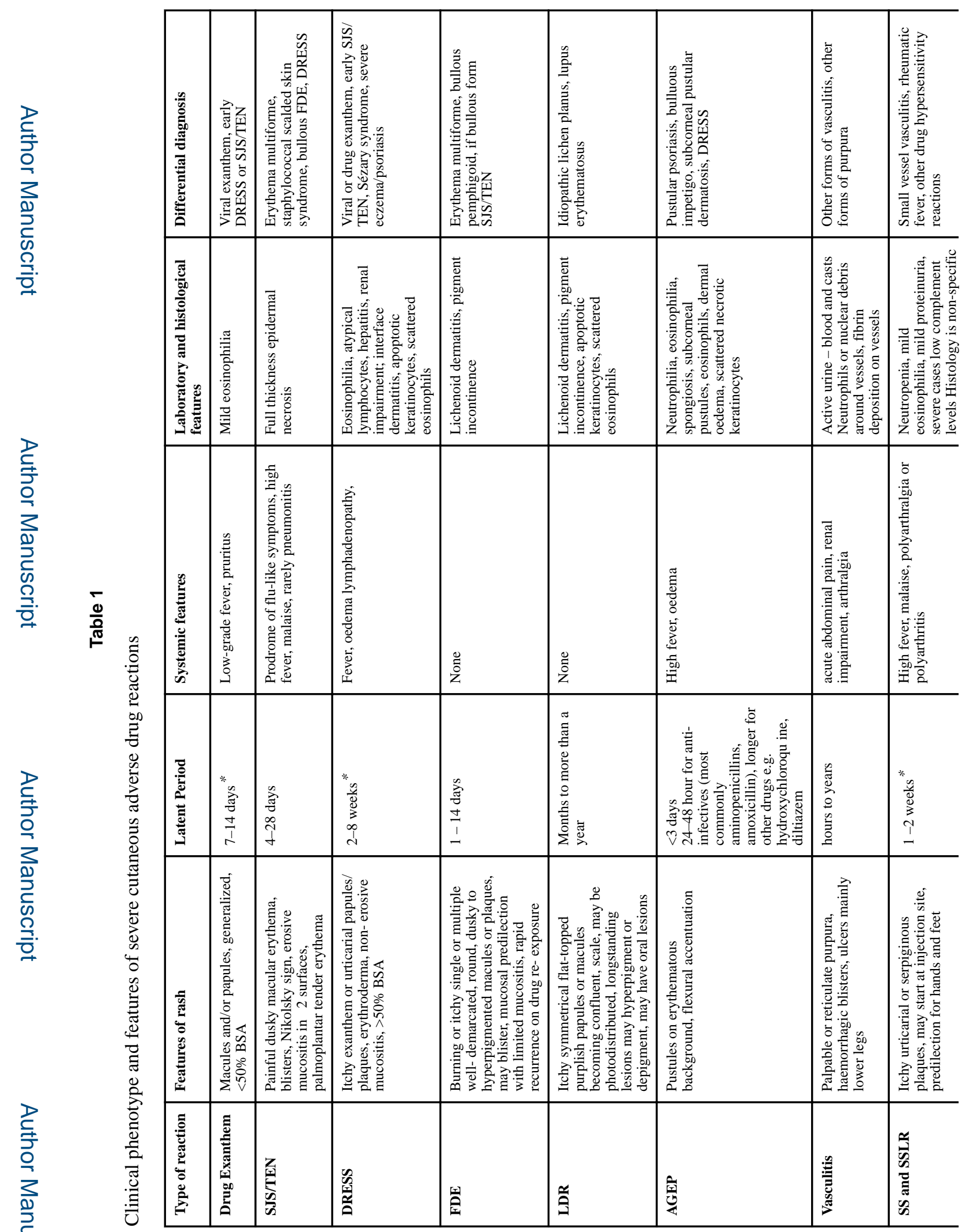

J Allergy Clin Immunol Pract. Author manuscript; available in PMC 2018 May 01. 


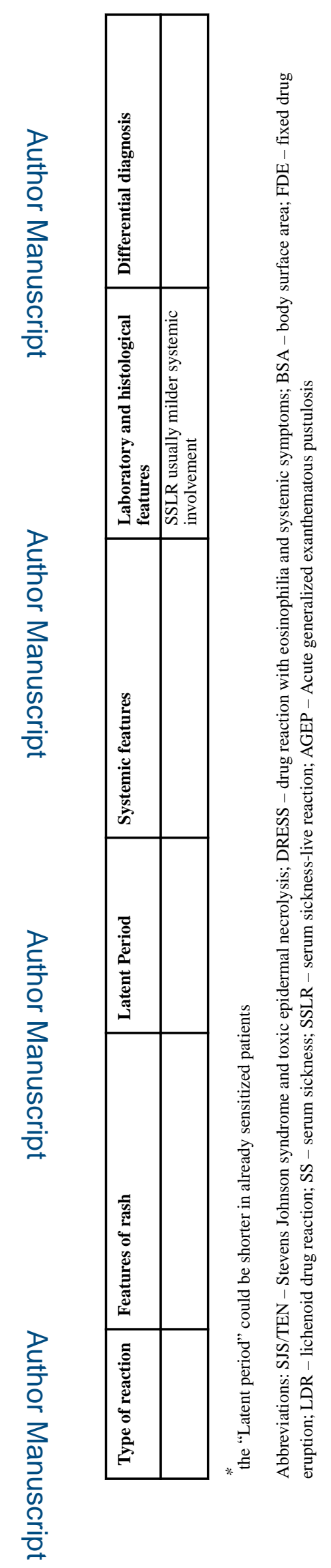

J Allergy Clin Immunol Pract. Author manuscript; available in PMC 2018 May 01. 


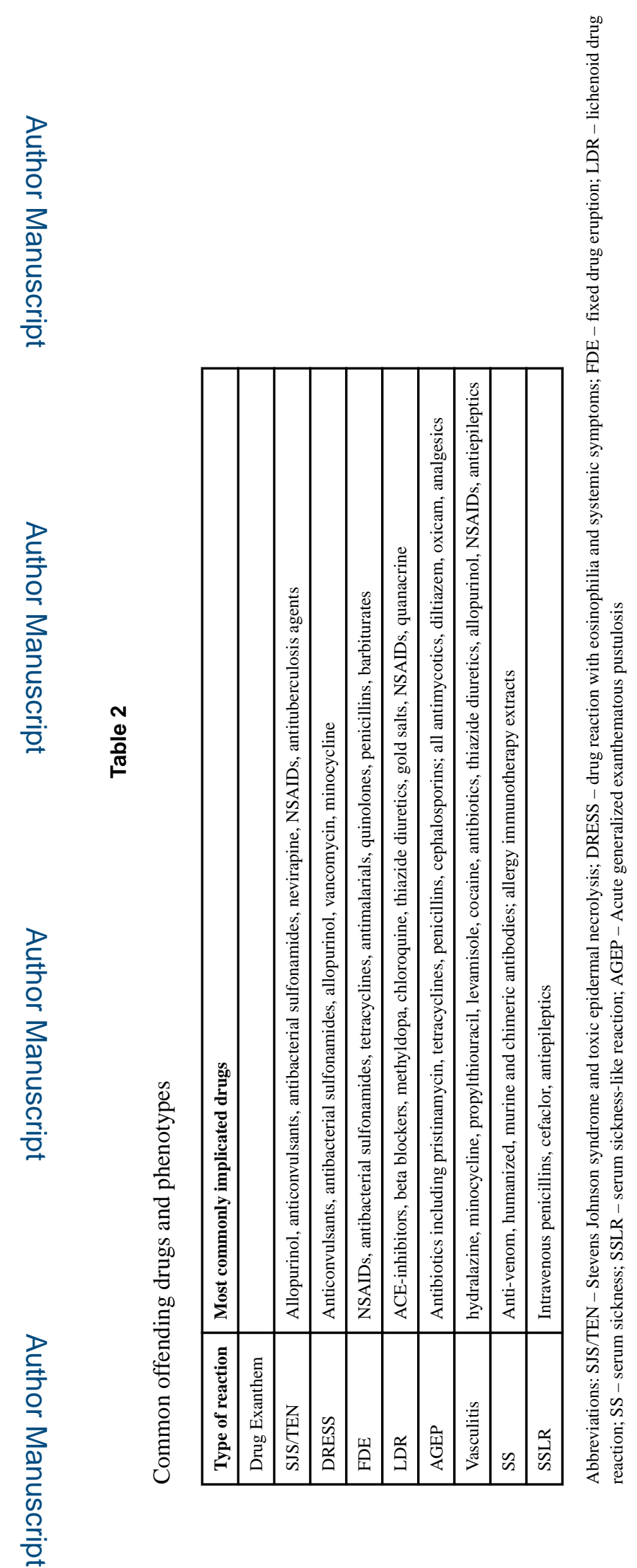

J Allergy Clin Immunol Pract. Author manuscript; available in PMC 2018 May 01. 


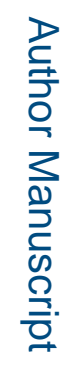

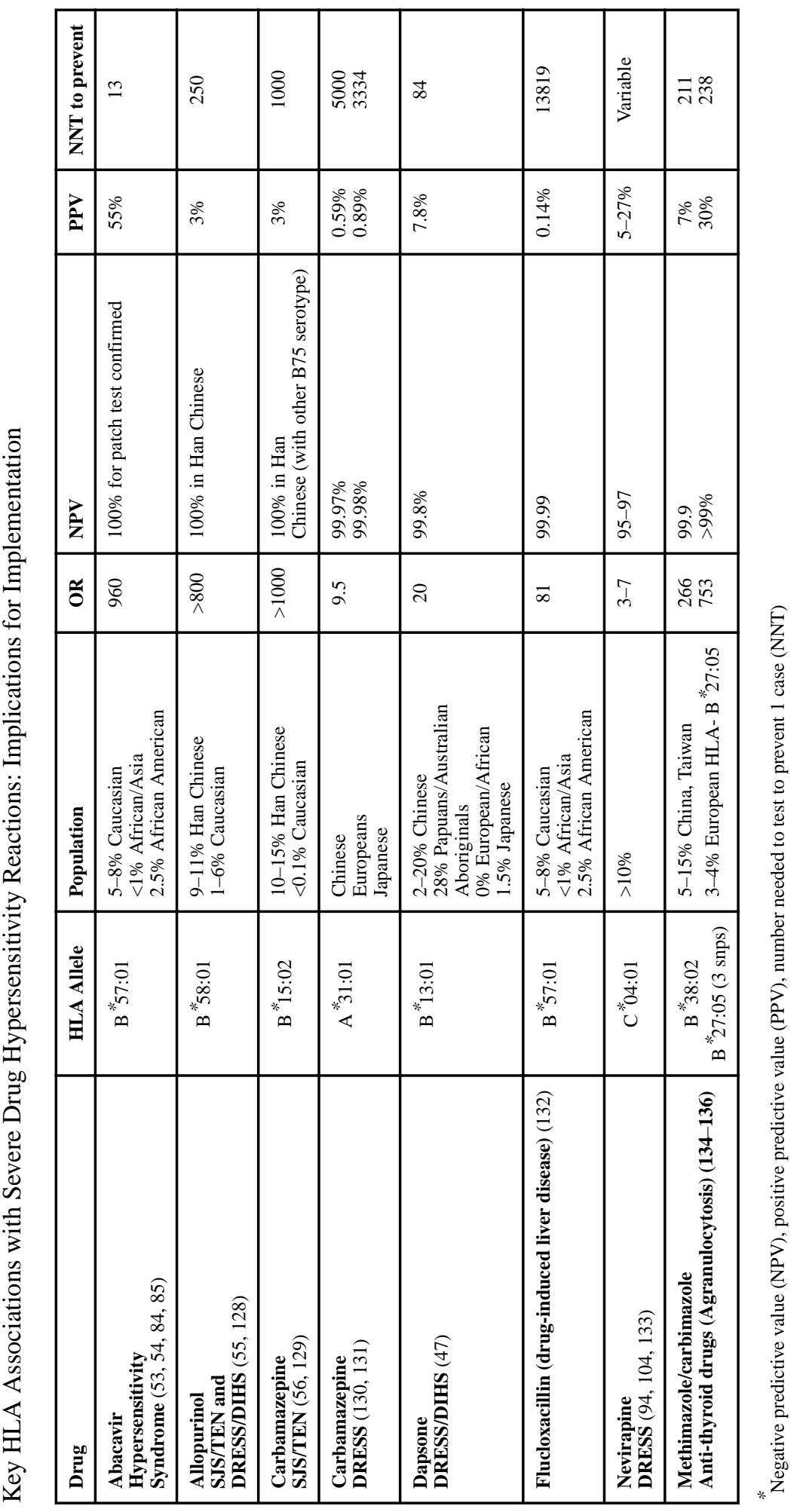

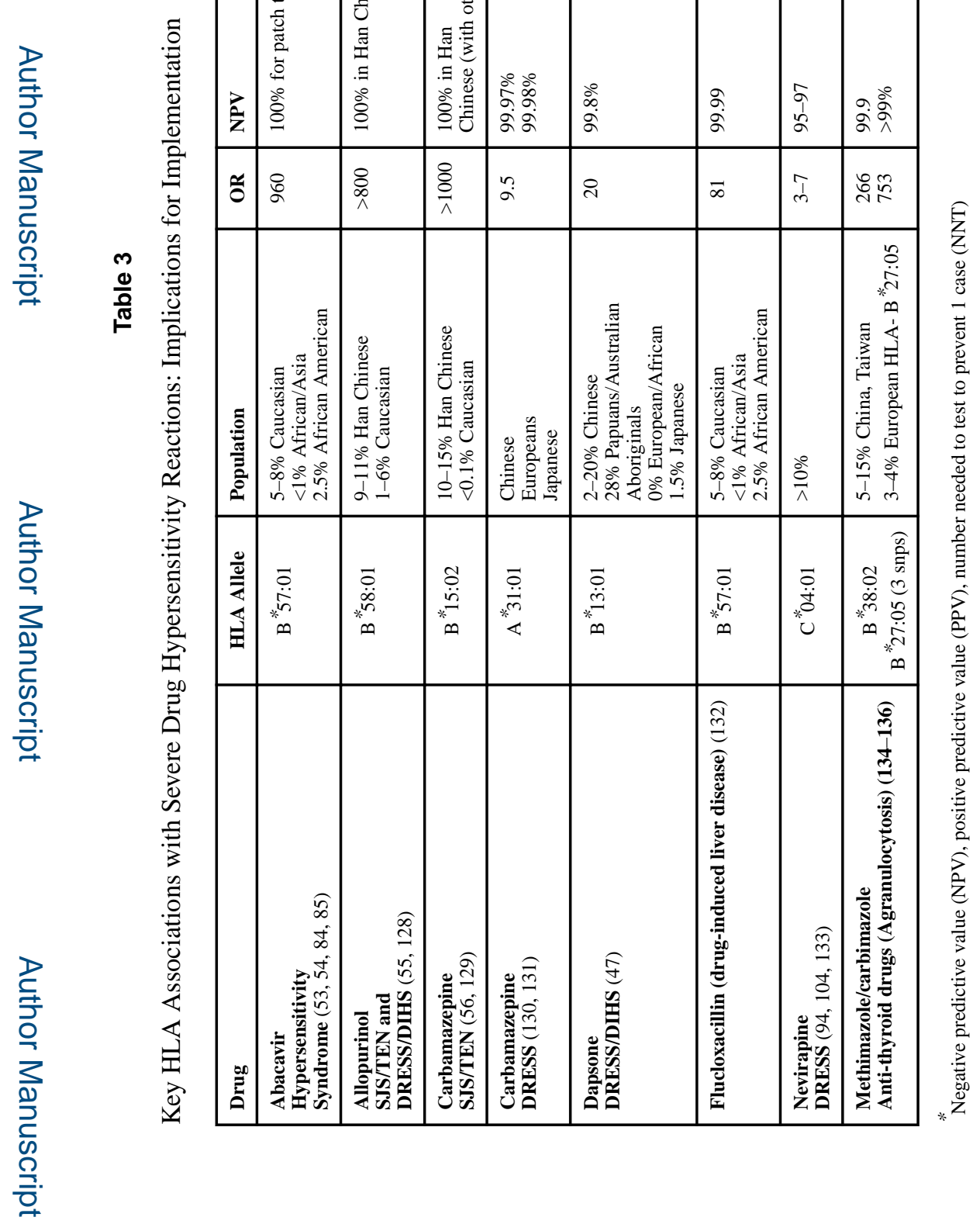

J Allergy Clin Immunol Pract. Author manuscript; available in PMC 2018 May 01. 


\section{Table 4}

Long-term sequelae of SCAR and follow-up requirements

\begin{tabular}{|c|c|}
\hline Type of reaction & Long-term sequelae \\
\hline Drug Exanthem & None \\
\hline SJS/TEN & $\begin{array}{l}\text { Skin: dyspigmentation, eruptive naevi, milia, nail dystrophy, alopecia, scarring, heterotopic ossification (137-140). } \\
\text { Ocular: sicca symptoms, trichiasis, corneal vascularization, corneal scarring, symblepharon, keratitis, blindness (141, } \\
\text { 142). } \\
\text { Oral: xerostomia, synechiae, chronic gingivitis, dental caries, periodontal disease, taste abnormalities, abnormal dental } \\
\text { development in children, candidiasis (142,143). } \\
\text { GIT: pancreatitis, colon necrosis, oesophageal stenosis and webs, microstomia, persistent intestinal ulcers (144-148). } \\
\text { Genitourinary: vaginal stenosis, labial fusion, hydrocolpos, haematocolpos, dyspareunia, vaginal dryness, urethral } \\
\text { stenosis (149). } \\
\text { Pulmonary: chronic obstructive bronchitis and bronchiolitis, bronchiectasis, pharyngeal and laryngeal scarring }(150,151) \\
\text { Autoimmune: Sjogren's syndrome, systemic lupus erythematosus, autoimmune thyroiditis (151). } \\
\text { Psychiatric: anxiety, depression (152). }\end{array}$ \\
\hline DRESS & $\begin{array}{l}\text { Skin: dyspigmentation, xerosis }(153) \text {. } \\
\text { Autoimmune disease: alopecia areata, diabetes mellitus type 1, autoimmune haemolytic anaemia, }>50 \% \text { have } \\
\text { autoantibodies, Graves disease }(153-155) \text {. } \\
\text { Genitourinary: progressively increasing risk of renal failure }(153) \text {. } \\
\text { Psychiatric: post traumatic stress disorder, anxiety, depression }(152,156) \text {. }\end{array}$ \\
\hline FDE & Post inflammatory hyperpigmentation $(38,39)$. \\
\hline LDR & Post inflammatory hyperpigmentation, depigmentation $(10,157)$. \\
\hline AGEP & None \\
\hline Vasculitis & $\begin{array}{l}\text { Skin: dyspigmentation, scarring } \\
\text { Genitourinary: Renal failure }\end{array}$ \\
\hline SS & Progressive glomerulonephritis, aplastic anaemia \\
\hline SSLR & None \\
\hline
\end{tabular}

Abbreviations: SJS/TEN - Stevens Johnson syndrome and toxic epidermal necrolysis; DRESS - drug reaction with eosinophilia and systemic symptoms; FDE - fixed drug eruption; LDR - lichenoid drug reaction; SS - serum sickness; SSLR - serum sickness-live reaction; AGEP - Acute generalized exanthematous pustulosis 